\title{
«Així com un camp de batalla»: A l'entorn de les imatges de tipus militar als sermons de Vicent Ferrer ${ }^{1}$
}

\author{
«Així com un camp de batalla»: \\ About the Military Imagery in Vincent Ferrer's Sermons
}

\author{
Josep Antoni Aguilar Àvila \\ Universitat Catòlica de València \\ josepantoni.aguilar@ucv.es \\ Recibido: marzo de 2019. Aceptado: junio de 2019
}

\begin{abstract}
Resum: El corpus sermonari de sant Vicent Ferrer és ric en símils i al-legories de tall bèl-lic. El present article analitza l'ús d'aquest tipus d'imatgeria per part del dominic valencià, principalment mitjançant la lectura comparada dels seus sermons amb els d'altres predicadors medievals i diversos tractats de predicació de l'època. En concret, hom centra l'atenció en tres aspectes de la presència d'aquesta mena d'imatges dins la predicació vicentina: a) la presentació de Jesucrist com un cavaller (Christus miles) que lluita contra el diable per tal de redimir la humanitat; b) el desenvolupament de similitudines complexes en què el conjunt de la cristiandat és presentat com una host en formació de batalla contra els vicis i les temptacions; i c) el recurs freqüent a l'al-legoria del castell espiritual, un símbol el significat del qual fluctua en funció de cada sermó.
\end{abstract}

Mots clau: sant Vicent Ferrer, imatges militars, artes praedicandi, similitudo, Christus miles

Abstract: Saint Vincent Ferrer's corpus of sermons presents a rich variety of military similes and allegories. The present paper analyzes the use of these images in Ferrerian preaching, and does it mainly by means of a comparative approach which takes into account also the work of other medieval preachers

\footnotetext{
1 Aquest treball s'inscriu en el projecte de recerca «La cultura literària medieval i moderna en la tradició manuscrita i impresa (VI)» (FFI2017-83960-P), que es desenvolupa a la Universitat de València amb el suport del Ministeri de Ciència e Innovació.
} 
and several Artes praedicandi treatises. Particular consideration has been given to three diferent aspects of the use of this sort of imagery in Ferrer's sermons: a) the portrayal of Jesus Christ as a knight (Christus miles) who jousts against the devil for human salvation; b) the elaboration of complex similitudines in which the whole of Christendom is represented as a host assembled in battle array against temptations and vices; c) the regular use of the spiritual allegory of the castle under siege, a symbol whose meaning fluctuates from sermon to sermon.

Key words: Saint Vincent Ferrer, military imagery, artes praedicandi, similitudo, Christus miles

\section{I.- INTRODUCCIÓ}

En un sermó per al primer divendres després de Pasqua, sant Vicent Ferrer compara la relació entre el cos i l'ànima amb una guerra oberta entre dos enemics mortals:

Sapiau que ja la persona naturalment ha guerra, car la carn batalle ab la ànima, e aquesta guerra és o ve naturalment, car los àngels no han aquesta contrarietat [...] E per ço la guerra que havem naturalment, per ço és necessària la pau interior. E com la haurem? Yo us ó diré: quan dos hòmens han guerra mortal, veus que no·s poden avenir sinó en una de dues maneres: o per concordança o per subjectió, e nom ha pus per concordança quan abduys se concorden a una voluntat, o per subjectió, e açò si la hu és pus poderós que l'altre. E llavors lo que menys pot ha's a sotmetre a açò que l'altre vol. E veus que axí·s fa la pau per subjectió e no per concordança, car bé li desplau, car fa-u per temor. Susaxí havem a fer nosaltres. Mas veus que no podem fer pau ab Déu ab concordança [...] Mas bé.s pot fer per subjectió. E com? Per dejunis, per almoynes, per oracions, etc. (Ferrer 1975-1988: VI, 20).

Com es pot veure, el missatge vehiculat pel valencià és molt clar: la carn s'ha de sotmetre a l'esperit i l'esperit a Déu, de la mateixa manera que en una guerra desigual és el més feble qui ha d'acabar subjugant-se als designis del més poderós. El que se'ns planteja en aquest fragment és una similitudo, recurs que a les artes praedicandi medievals servia per a explicar un determinat concepte moral o teològic mitjançant una situació hipotètica amb la qual s'establien una sèrie d'analogies o paral-lelismes, com és el cas. ${ }^{2}$ De fet, en els sermons de sant Vicent es pot percebre un cert gust pels símils, metàfores i al-legories de tipus bèl-lic o castrense, fins al punt que recentment hom hi ha vist - encertadament, crec_ - una «línia de força» dins la seua predicació (Ysern 2019: 289). En aquest sentit, l'objectiu del present paper és d'oferir una aproximació sense vocació d'exhaustivitat a l'ús que el dominic fa d'aquesta mena d'imatges, un

2 Sobre la similitudo i el seu paper en els textos vicentins, vegeu Cátedra (1994: 210) i Ysern (2015: 68-73). 
ús que, com espere demostrar, no sols condiciona el contingut o el desenvolupament temàtic dels sermons on apareixen, sinó també el disseny i l'estructura d'alguns d'ells. Els exemples seleccionats per a l'anàlisi procedeixen en bona part del corpus sermonari vicentí transmés en llengua catalana, tot i que subsidiàriament he jutjat oportú de considerar de manera conjunta les diferents redaccions, catalanes o llatines, que se'ns han conservat d'un mateix sermó, sobretot en aquells casos en què l'acarament d'aquestes versions posa de manifest divergències interessants en el tractament o desenvolupament d'una imatge determinada.

Per altra banda, el lector m'haurà de disculpar que, a fi de donar un cert ordre al tema abordat, m'haja permés la llicència de donar a la meua intervenció una estructura trinitària, i de presentar-la, a més, a la manera de les divisions rimades amb què mestre Vicent $i$ tants altres predicadors medievals solien dividir la matèria dels seus sermons. Així doncs, les tres parts que abordaré en aquestes pàgines seran les següents:

Parlaré, en primer lloc, del duel abstinencial.

En segon lloc, de la batalla campal.

I, en tercer i darrer lloc, del setge espiritual.

Com hom deu haver imaginat, en aquestes tres categories he tractat d'encabir diversos tipus d'imatges relacionades amb la guerra emprades per sant Vicent: en particular, en la primera, analitzaré el tractament que rep en els seus sermons el motiu del Christus miles —ço és, la presentació de Jesucrist com un cavaller que, per tal de redimir la humanitat, s'enfronta en una justa singular amb Llucifer; en la segona, aquells casos en què el conflicte entre el bé i el mal és descrit pel sant com una batalla a camp obert entre dues hosts, les del poble cristià i dels diables; en la tercera, la presència del símbol al-legòric del castell assetjat en la predicació vicentina. Òbviament, no es tracta ni de bon tros d'una classificació perfecta ni exhaustiva, però em sembla que pot resultar profitosa a efectes ordenadors i orientatius.

\section{II.- DUEL ABSTINENCIAL: EL CAVALLER JESUCRIST}

D'entrada, convé assenyalar que el recurs a símils, analogies i al-legories de caràcter bèl-lic en la literatura religiosa medieval és un fenomen fàcilment explicable si hom té present que, de fet, ja a la mateixa Bíblia sovintegen les imatges d'aquest mateix tipus. A tall il-lustratiu, basta recordar que a la Carta als Efesis sant Pau exhorta els fidels cristians a guarnir-se amb l'armadura simbòlica de les virtuts per tal d'enfrontar-se a les temptacions del diable (Ef 6, 11-17); que al Càntic dels Càntics l'amic lloa la seua amiga tot comparant la seua bellesa a la d'una host amb els estendards desplegats i en formació de batalla $(\mathrm{Ct} 6,4)$; i, encara, que al Llibre de Job el pacient i sofrent protagonista d'aquesta obra afirma, tot greu: «Militia est vita hominis super terram» (Jb 7, 1). En definitiva, en l'aspecte que ara ens ocupa la teologia i la predicació medievals treballaven en bona part a partir d'idees i imatges que ja es trobaven 
in nисе a les Escriptures, desplegant-les i reelaborant-les fins a extrems que, com veurem, podien arribar a ser certament molt sofisticats. ${ }^{3}$

Considerem, per exemple, el cas de la citació jobiana suara al-ludida, que fou bellament glossada al cap. 1 del Segon de Lo Crestià, la vasta obra enciclopèdica del franciscà gironí Francesc Eiximenis. En efecte, en aquest text Eiximenis ens explica que si la vida és una milícia, ço és, una guerra, qui pren part en aquesta guerra, és a dir, l'ésser humà, no és cap altra cosa que un miles, un guerrer, un cavaller. Naturalment, a partir d'aquest punt el fil inferencial es pot seguir estirant a cor què vols, incorporant-hi noves correspondències: així, l'escenari en què el cavaller desenvolupa la seua professió, l'ofici de les armes, és el camp de batalla (que, metafòricament parlant, seria tot aquest món); en aquest camp de batalla, l'esperen els enemics amb els quals s'haurà de combatre (que en són tres, des del punt de vista de la teologia cristiana: el dimoni, el món i la carn); aquests enemics, enganyívols i traïdors, han parat aguaits i paranys contra la seua vida (les temptacions i els vicis); per defensar-se d'aquests embats, el cavaller necessitarà guarnir-se d'un bon arnés defensiu i ofensiu (en el cas dels cristians, una panòplia d'armes espirituals, conformada per les virtuts teologals i cardinals, amb la pràctica de les quals podrà superar les escomeses de l'enemic):

E aquesta és la raó per què Job, capítulo VII ${ }^{\circ}$ de son llibre, diu així: «Milicia est vita hominis super terram», jatsia que, segons que altra translació de la Bíblia posa, lla on nós diem «milícia» haja «temptació», e quaix tot s'avé a un propòsit, car la sua intenció és a dir que «tota la vida de l'hom sobre la terra és així com una bella cavalleria» d'un noble cavaller que s'ha a combatre ab son adversari per haver corona e gran glòria per la sua victòria. E per tal, pus que així és que a Déu plau que tota la vida present de l'hom sia cavalleria e treball e misèria, per tal negun no es deu [...] esmaiar si es veu en pressura o veu que és perseguit o difamat o en malícia posat, o aperduat en les coses temporals, ni si és tribulat o afligit per fam o per set, o per fred o per calor, o per pobrea o per neguna aflicció corporal; car si aitals coses no fossen, la present vida no fóra camp de cavalleria ni temptació nostra, ni l'hom no fóra nat a treball [...] Ans, tot així com lo cavaller qui ben guarnit entra en lo camp en què no batalla ni poc ni molt ni en res no hi treballa, no aconsegueix negun guardó ni fama ni neguna novella corona per neguna proea ni aptea ni fortalea ni virtut que haja ensenyada, així l'home qui ab neguna de les damunt dites tribulacions no vol ni ha de fet negun contrast ni batalla, no cal esperar ni alegrar en negun guardó que Déus li do per son treball ni per sa victòria. Per què apar que així com al prous e valent cavaller és gran honor e glòria que no sia pintat ni polit ni ornat així com a donzella, ans tota la glòria sua és que ell sia tot nafrat, colpat, e tot gavanyat per grans e poderosos colps e esvaïments e bata-

\footnotetext{
3 Aquest conjunt d'imatges conformen el topos de la militia spiritualis, els orígens del qual es poden rastrejar ja als primers textos de la història del cristianisme (Harnack 1981), especialment a les epístoles paulines (Krentz 1993 i Gupta 2017), i que conegué en els segles medievals una àmplia fortuna mercés a l'exegesi de la tradició patrística i monàstica (Leclercq 1992, Smith 2011 i Ysern 2019: 287-293).
} 
lles e contrasts que ha haüts ab sos enemics dels quals és finalment escapat ab victòria, així al ver cristià és gran glòria que en totes parts on se gir se tròpia e es conega ésser estat colpejat e gavanyat e esvaït e bé macat per les contínues batalles que ha haüdes ab la carn e ab lo món e ab lo dimoni, e ab totes les altres malícies e adversitats damunt dites, qui tostemps, dins e defora, dessús e dejús, davant e darrera, lo tenen e l'han tengut assetjat, enrevironat e ocupat en batallar e en guerrejar sens negun repòs, nit e dia (Eiximenis 1983: 50-51).

De la mateixa manera que un dels components fonamentals de l'ethos cavalleresc és l'emulació de les proeses dutes a terme pels grans cavallers del passat, els cristians poden emmirallar-se en un model insuperable de capteniment, el de Jesucrist mateix, que, de fet, és presentat ben sovint com un cavaller no sols en les lletres, sinó també en la iconografia dels segles medievals. En el camp de la literatura, el motiu del Christus miles apareix, per exemple, al poema narratiu Piers Plowman, compost cap al darrer quart del segle XIV per William Langland, que conté una sèrie de visions oníriques experimentades pel personatge principal del llibre, el mateix Piers Plowman, entre les quals té una especial rellevància la figura de Jesus the Jouster, cavaller que, per tal de redimir la humanitat, es va vestir d'incògnit (és a dir, amb carn humana) i va venir al món per enfrontar-se amb el dimoni, que no el va reconéixer fins després d'haver estat vençut per ell (noteu que la manera com es presenta l'Encarnació en aquesta obra recorda l'estratagema de la disfressa que els herois de la literatura artúrica empren per evitar de ser coneguts quan emprenen alguna aventura o es presenten en algun torneig). ${ }^{4}$

En les seues homilies, els predicadors medievals van explotar també la imatge del Crist-cavaller, de vegades amb resultats força curiosos, com permet de constatar la lectura dels dos textos que presentaré a continuació, ambdós adduiits per la crítica en comentar els versos del Piers Plowman a què tot just m'acabe de referir. ${ }^{5}$ El primer és un fragment d'un sermó llatí del frare franciscà Albert de Metz, personatge documentat a inicis del segle XIV, on es pot llegir una similitudo d'un ben destacat caire novel-lesc. Aquesta adopta, en efecte, la forma d'un breu relat, mitjançant el qual el frare explica l'Encarnació i la missió redemptora de Jesucrist. El protagonista d'aquest relat és un jove cavaller que va sacrificar la seua vida per tal de salvar una donzella de la cruel opressió d'un tirà:

Fuit quaedam puella a quodam tyranno graviter impugnata; nec habebat virum aliquem qui posset eam defendere contra tyrannum qui volebat sibi heredita-

4 «This Jesus of his gentries wol juste in Piers armes, / in his helm and in his haubergeon -humana natura. / That Crist be noght biknowe here for consummatus Deus, / in Piers paltok the Plowman this prikiere shal ryde; / for no dynt shal hym dere as in deitate Patris» (Passus XVIII, vv. 22-26; Langland 1987: 220).

5 Sobre aquesta qüestió, vegeu Gaffney (1931) i Warner (1996). Pel que fa a la imatge del Christus miles en la cultura medieval, vegeu Kaeuper (2009: 129-140) i les referències que s'hi citen; per la seua banda, Wenzel (1986: 246-249) analitza la presència d'aquesta figura en la predicació. 
tem suam auferre. Saepe clamabat ad Dominum ut liberaret eam de potestate illius tyranni. Tandem venit quidam juvenis miles, qui obtulit se pro ea pugnaturum. Tantum dixit ei quod nihil quaerebat ab ea, nisi ut, si vinceret tyrannum et viveret, quod haberet illius memoriam; si autem moreretur, custodiret tunicam suam ad amandum in memoria. Accessit dies conflictus. Ille juvenis miles pugnavit cum tyranno a mane usque ad vesperum et devicit tyrannum; sed vulneratus fuit graviter quinque vulneribus, et in quinto mortuus fuit. Tum illa puella accepit tunicam ejus tinctam suo sanguine, ut ille rogaverat, et posuit in camera sua, in tali loco quod ipsam videbat quoties intrabat cameram, et ingrediens flebat pro amore illius, et saepius ibat in cameram ut videret tunicam et haberet amici sui memoriam (Biblioteca Nacional de França, ms. lat. 14952, f. 68; citat per Gaffney 1931: 162).

Acabat el relat, el frare explicita el sentit metafòric de cadascun dels personatges i els elements que hi apareixen. Així, la donzella de la història simbolitza la condició humana, sotmesa d'ençà del pecat original sota el jou tirànic del diable, i el campió que l'allibera d'aquesta servitud és el mateix Jesús, ferit mortalment de cinc ferides en el combat de la creu:

Spiritualiter puella ista fuit humana natura, tyrannum Diabolus, miles Christus, qui accepit tunicam albam ad armandum se contra Diabolum, scilicet carnem in utero Virginis. Bene fuit alba quia peccatum non fecit [...] et pugnavit contra Diabolum usque ad nonam, et vulneratus fuit quinque vulneribus, cum lancea lanceatus et mortuus: sed tamen Diabolum devicit. Tu ergo, o anima christiana, accipe tunicam, scilicet passionis sum memoriam, et pone ante oculos tuos, et tunc superabis omnes adversarios tuos (ibidem).

El segon text pertany a un altre sermó que va circular en diverses redaccions amb el títol força eloqüent de Sermo de Tabula Rotunda. ${ }^{6}$ El seu autor, de qui no en sabem el nom, va voler explicar en aquesta peça per quina raó de les tres persones que conformen la Trinitat fou precisament la del Fill la que va baixar a aquest món a combatre's amb el diable. Ho fa amb una similitudo o exemplum d'un ben explícit rerefons artúric, en què el Regne del Cel es transforma en una mena de Camelot empíria i les persones del Pare, el Fill i l'Esperit Sant en cavallers pars d'una Taula Rodona celestial. A l'hora de llegir-lo, convé tenir en compte que la Taula Rodona, aquest conegut escenari de la ficció artúrica, va donar nom històricament a una pràctica esportiva cavalleresca perfectament documentada en els fastos i tornejos que se celebraven a les corts medievals, que, amb algunes variants, funcionava poc dalt o baix com es descriu en el text: hom erigia un cadafal a manera de castell, als murs del qual els cavallers que eren de la partida penjaven els seus escuts; tot cavaller que volgués enfron-

${ }^{6}$ Sobre les diferents versions que ens han pervingut d'aquesta peça, vegeu Wenzel (1986: 234, n. 68). 
tar-se a alguns dels cavallers del castell s'acostava als murs i tocava l'escut de l'adversari desitjat, que tot d'una eixia a enfrontar-se-li: ${ }^{7}$

Dicitur: «Qui propter nos homines et propter nostram salutem descendit de celis» in simbolo. Set quare cicius descendit Filius quam Pater vel Spiritus Sanctus? Vobis dicam per exemplum. Legitur in gestis Arturi quod habuit milites nobiles de Tabula Rotunda et quando congregabantur simul, singuli super parietem castelli pendebant sua scuta. Et si quis scutum alicuius tangebat, possessor scuti cum tangente pugnabat. Ad propositum: Tres persone Trinitatis possunt vocari milites Rotunde Tabule, quia omnes sunt equales virtutis et potencie. Anima Ade electa est castellum a Trinitate, in qua Pater posuit scutum potencie [...] Filius posuit scutum sapiencie [...] Spiritus Sanctus posuit scutum gracie, qua impletus erat ardenti amore et gracia. Set diabolus tetigit scutum Filii et non Patris nec Spiriti Sancti [...] Ideo Filium oportebat descendere et defendere scutum et pugnare cum diabolo (Oxford, Magdalen College, ms. 93, f. 144; citat per Warner 1996: 136-137).

Hom haurà comprovat que, en tots els textos fins ara adduïts, el conflicte entre Jesucrist i el dimoni és presentat com un duel cavalleresc. Amb aquests precedents, no ens haurà d'estranyar de trobar-nos entre les homilies vicentines un passatge com el que discutirem tot seguit, relatiu a les tres temptacions de què Crist fou objecte per part del diable durant el seu dejuni de quaranta dies al desert; forma part d'un sermó per al primer diumenge de Quaresma, construït sobre el tema de Mt 4, 11 («Ecce angeli accesserunt et ministrabant ei»). He jutjat oportú de reproduir, disposades conjuntament, quatre de les redaccions que ens han pervingut d'aquest sermó, ${ }^{8}$ atés que la consideració conjunta d'aquestes versions presenta, em sembla, diversos avantatges: a) en primer lloc, contribueix a aclarir la intel-lecció de passatges de sentit fosc o incomplet, que sovintegen en aquelles redaccions més breus i degudes al treball de reportadors i transcriptors que anotaven apressadament el sermó pronunciat pel predicador; b) en segon lloc, i com a punt molt relacionat també amb l'anterior, permet de detectar i esmenar lliçons errònies en el text d'una determinada redacció a partir de l'examen de les altres; c) en tercer lloc, ens posa al davant un mapa de les divergències de contingut detectables entre les versions a l'abast; $d$ ) en quart i darrer lloc, facilita la tasca de l'editor i estudiós interessat a consignar i analitzar les fonts invocades pel valencià, mitjançant la consulta d'aquelles redaccions més detallades a l'hora de consignar la procedència de les citacions incloses en els sermons: ${ }^{9}$

${ }^{7}$ El lector familiaritzat amb les lletres catalanes medievals recordarà que a la Crònica de Ramon Muntaner (cap. 179; Muntaner 2011: 299-300) es descriu una taula rodona d'aquest estil, i que al Tirant lo Blanc (caps. 71-72; Martorell 2004: 285-288) el toc dels escuts és el sistema amb què el cavaller Tirant requereix de batalla els quatre cavallers dels lleons coronats.

${ }^{8}$ Les diferents versions conservades d'aquest sermó han estat catalogades per Perarnau (1999: 483 i 553).

9 Sobre aquests avantatges, vegeu també Renedo (2007). 


\section{Sermons, CLXI}

Mas ara, pensat que aquella temptació o batalla fo axí com la batalla dels cavallers que fan en camp clos, e lo rey té lo camp segur, e los parents de aquells estan los uns a la una part e-ls altres a l'altra, sperant qual d'ells haurà victòria. E quan la hu ha haüda victòria, veus que $\cdot$ ls parents de aquell toquen les trompetes e fan gran festa. Axí fon de aquesta batalla de Jesuchrist: lo camp clos fo lo desert, e los amichs de Jesuchrist, ço és los àngels, estaven de la una part, e de la altra Lucifer e tots los dimonis, amichs de Lucifer. E diu lo Mestre de les Ystòries Scolàstiques que aquell matex dyable que temptà Adam, aquell matex temptà a Jesuchrist. E veus que Jesuchrist hagué'n victòria, vencent aquell, e llavors tots los dimonis qui eren aquí de part de Sathanàs ploraven, e los amichs de Jesuchrist feren gran goyg (Ferrer 1975-1988: V, 135).

\section{Sermons de Quaresma, VIII}

Diu: «Ecce angeli accesserunt et serviebant ei». Com fo? Vejats: quan dos cavallers deuen batallar en un camp clos, alt en un cadafalt està lo rei, que assegura lo camp; los amics dels primers batallants estan a part, e quan lo u és vençut, fuig ab sos amics e parents, e al que venç, los amics s'hi acosten $a b$ les trompetes sonants. Grans prínceps, ço és, Jesucrist, príncep de sanctedat, e Llucifer, príncep de pecat; Déu lo Pare estava alt, com mirava aquell camp, e los àngels d'una part e los diables de l'altra part. Les armes de Llucifer, llança, spasa e darga [sic!], e ab aquelles armes havia vençut tants. Lo diable era lo temptador: començà-li a llançar la llança, pecat de gola; e puis, ab l'espasa de vanaglòria, l'espà se trencà, e ab la daga de avarícia volc-lo ferir. E Jesucrist li féu caure la daga, e lo diable Llucifer fuig. Oh, si els haguésseu hoïts los àngels, dients ab gran alegria: «Viva! Viva lo fill de la Verge Maria!» (Ferrer 1977: I, 94).

\section{Ed. Colònia}

«Ecce angeli accesserunt». Et nota similitudinem et poteritis intelligere qualiter fuit. Quando duo magni domini seu principes faciunt duellum in campo clauso, ubi Rex tenet campum securum, et amici et exercitus utriusque expectant finem hinc inde, et facto prelio, victus cum suis fugit, et servitores et amici victoris cum gaudio ad eum accedunt, sibi necessaria ministrando. Sic Christus et Lucifer maiores principes mundi, ut dicit Magister Histo-riarum (sed diversimode, nam Christus est Princeps sancti-tatis, et Lucifer iniquitatis) hodie fecerunt duellum, et Deus Pater tenuit campum securum. Christus autem, ut dicit Crisostomus, precepit angelis, ut ab eo elongarentur, ne a Lucifero viderentur; idem fecit Lucifer de suis; et soli ipsi duo intraverunt campum. Et arma dyaboli fuerunt tria, scilicet lancea, ensis et daga. Cum lancea superbie et vane glorie, cum ense gule et cum gladio avaricie Christum temptavit, et accessit; nam ipse Lucifer cum istis armis plures occiderat, sed Christo in nullo nocuerunt, sed victus fugit (Ferrer 1485: s.f.).

\section{Ms. d'Aiora}

Et ut cognoscatur qualiter fuit ista ministracio, pone exemplum de duobus preliatoribus, qui intrant in campum, et in una parte stant gentes unius, et in alia gentes alterius prelian- cium, et Rex stat in truna cum Curia sua. Et 
omnes spectant quid erit de eis, et nullus audet eos iuvare. Et finaliter cum unus est devictus, illi de parte sua omnes fugiunt, et illi de parte vincentis omnes clamant, et vocifferant cum tubis: «Viva, viva!». Et sic cum magno honore sociant eum in Civitatem. Sic hodie duo milites maximi tocius mundi intraverunt in campum prelii. Maximi, quia maximus omnibus hominibus est Christus Salvator noster, et inter Angelos bonos et malos maior erat Luciffer. Isti ergo duo tam magni milites intraverunt hodie in campum prelii. Rex qui tenebat campum securum, est Deus Pater, qui de turri eternitatis sui intuebatur quod futurum erat de eis. Cum Iesu erant quam plurimi Angeli, et cum Luciffero erant quam plurimi demones. Et sic, omnibus intuen-tibus, inceperunt preliari. Et primo Luciffer iniecit tres ictus ad Iesum. Primus fuit cum lancea, qua percussit Adam, et hoc cum dixit ei: «Dic, ut lapides isti panes fiant». Et sic pro primo ictu Luciffer fuit devictus. Secundo, iniecit ictum cum axia, qua percussit Aaron fratrem Moysi, et Mariam uxorem eius. Et Iesus opponit ei bacinetum Sancte Scripture, cum dixit: "Non temptabis», etc. Tertio, iniecit ictum cum ense, quo percussit Saul, qui fuit malus in sua dominacione. Sed Christus devicit eum cum auxilio reverencie et honoris Dei, opponendo textum Sancte Scripture: «Dominum Deum tuum», etc. Et sic Lucifer fuit devictus, et fugit cum omni sua familia. Et tunc accesserunt Angeli clamantes: «Viva, viva Iesus, Filius Virginis Marie!» (Ferrer 1995: 53-54).

Com es pot apreciar, en totes quatre versions se'ns presenta una similitudo que, a grans trets (i deixant de banda només de moment algunes variants de les quals m'ocuparé una mica més avall), funciona així: ens hem d'imaginar dos cavallers que entren en una lliça o camp clos, l'espai on, com és sabut, solien celebrar-se les justes o tornejos; tots dos s'han presentat al lloc acordat acompanyats pels seus amics i familiars, que ara han pres posicions a les graderies situades a banda i banda del camp i seran espectadors de l'enfrontament (naturalment, i com passa sovint en el futbol, els tifosi d'un i altre bàndol no es barregen: cadascuna de les aficions se situa en una zona diferent de l'estadi). En un altre cadafal, més elevat, hi ha el rei, que actua com a garant de la neutralitat del camp i jutge de la batalla. Quan tot és a punt, el combat comença, normalment quan el cavaller reptador (és a dir, aquell que prèviament ha desafiat l'altre a batre's i que, per tant, amb el seu desafiament, ha provocat el combat) escomet el seu oponent. Acabada la batalla, el vençut, si sobreviu, es retira o fuig del camp capcot i avergonyit, juntament amb els seus partidaris; per la seua banda, el vencedor deixa el camp agombolat pels seus amics, que celebren la victòria amb exclamacions de joia i càntics. Tot seguit sant Vicent ens explica com cal interpretar a la divina tota la situació plantejada, detallant els paral·lelismes existents entre aquesta i l'episodi de les temptacions al desert: els cavallers que van entrar al camp foren Jesucrist i Llucifer; els amics que els acompanyaren foren, respectivament, els àngels i els dimonis; el rei situat al cadafal més elevat fou Déu Pare, que es mirava el combat des del cel; el reptador, o millor dit temptador, fou Llucifer, que escometé Jesús amb tres armes potents per tal de fer-lo pecar mortalment (es tracta, és clar, de tres armes al·legòriques: la llança de la gola, l'espasa de la supèrbia i la daga de l'avarícia); fou Jesucrist qui al remat d'endugué la victòria, jubilosament celebrada pels àngels, que s'acostaren tot d'una al Fill de Déu per a servir-lo. 
Aquest és l'esquema general de la similitudo, esquema que en cadascuna de les redaccions es desplega incorporant-hi algunes variants interessants (bé en forma de petits canvis, bé en forma de detalls o consideracions addicionals). Així, per exemple, en les redaccions núms. 1 i 3 es precisa, bo i remetent a l'autoritat de la Historia Scholastica de Pere Comèstor (Historia Evangelica, cap. 35; PL 198, col. 1556), que el dimoni que s'enfrontà a Jesucrist fou el mateix Llucifer que havia temptat i derrotat Adam en l'episodi del pecat original. D'altra banda, a la redacció núm. 3 es cita també sant Joan Crisòstom (Opus imperfectum in Matthaeum; PG 56, col. 667), assimilat possiblement per mitjà de la Catena Aurea de sant Tomàs d'Aquí (Catena Aurea in Matthaeum, cap. 4, lectio 4; Aquí 2006-2016: I, 294), per tal d'assenyalar que, una mica abans de l'inici de la batalla, Jesucrist va ordenar als seus àngels que s'apartaren una mica del lloc i que no intervingueren en la contesa, i que Llucifer va fer el mateix amb els seus diables (un apunt que, ben mirat, recorda una mica els duels del Far West!).

Encara més detalls ressenyables: el lloc des del qual Déu Pare va observar el duel no fou en realitat, segons el text núm. 4, cap cadafal ni trona, sinó la «turris aeternitatis», ço que li permetia de conéixer d'avantmà quin seria el desenllaç de l'episodi. Cal posar de relleu, també, que les armes amb què el reptador Llucifer va escometre Jesucrist coincideixen en les redaccions núms. 2 i 3: llança, espasa i daga (per cert, en aquest punt el text núm. 2 incorre en una lectio fâcilment subsanable, perquè ens parla d'una darga, és a dir, d'un escut de cuir, que no era considerada una arma ofensiva, sinó defensiva: el context $\mathrm{i}$ la consulta de la resta de versions justifica plenament l'esmena per daga); ara bé, l'equivalència al-legòrica que s'atribueix a cadascuna d'aquestes armes difereix lleugerament entre una i altra redacció: en tots dos casos, la daga representa l'avarícia o cobejança, però si a la núm. 2 es parla de la llança de gola i l'espasa de supèrbia o vanaglòria, a la núm. 3 trobem una associació de sentit invers: la llança és la supèrbia i l'espasa, la gola.

El combat espiritual rep un tractament narratiu diferent i una mica més elaborat a la versió núm. 4: per començar, en aquest cas les armes ofensives emprades pel dimoni són la llança de gola, l'atxa de supèrbia i l'espasa d'avarícia. Convé advertir que, tot i que aquest simbolisme no és explicitat a la lletra en el text, sí que es pot deduir ben fàcilment tenint en compte que, en introduir cadascuna de les armes, aquesta és posada en relació amb un determinat personatge de l'Antic Testament conegut per haver incorregut en algun dels pecats que ens ocupen: així, el primer colp assestat pel diable fou el de la llança, la mateixa amb què va ferir Adam, que va menjar del fruit prohibit (Mt 4,4; pecat de gola); el segon fou el de l'atxa, la mateixa amb què foren colpits Aaron i la seua muller Maria, que criticaven Moisés i es consideraven més dignes que ell del favor que Déu li concedia (Nm 12, 10; pecat de supèrbia); el tercer fou el de l'espasa, la mateixa que va provocar la caiguda en desgràcia de Saül, que, després d'haver vençut els amalequites, va consentir que la seua tropa es fes amb el bo i millor dels ramats dels enemics, desobeint així el mandat rebut de Déu, que havia ordenat l'extermini de tots els éssers vivents de la tribu d'Amalek (1 Sa 15, 1-23; pecat d'avarícia). Aquesta mateixa versió reprodueix també els mots amb què Jesús rebutja cadascuna de les temptacions, que són presentats pel predicador com les armes defensives amb què un cavaller resisteix els embats del seu opo- 
nent: de fet, en referir el colp d'atxa descarregat pel diable, el sant ens diu que Jesucrist l'aturà amb el bacinet de la Santa Escriptura, bacinet que simbolitza les paraules amb què Jesús refusà la segona de les temptacions: «Non tentabis Dominum Deum tuum» (Mt 4,7). Finalment, la manera com els àngels celebren el triomf de Crist també varia segons els textos: a les versions núms. 2 i 4, per exemple, prorrompen en càntics i exclamacions que són reproduïdes en estil directe al sermó: «Viva! Viva lo fill de la Verge Maria!».

Finit el relat de la batalla, sant Vicent glossa el sentit del passatge evangèlic que constitueix el tema del sermó: «Ecce angeli accesserunt et ministrabant ei». En concret, el valencià es demana en què consistí aquest servei angelical. A parer seu, després de quaranta dies de dejuni, només podia tractar-se d'un «dinar de vianda». De fet, ens explica de quina manera aquesta vianda fou posada a mans del Messies: després de derrotar el diable, Jesús va ordenar als seus àngels que portaren les noves del triomf a sa mare i que li demanaren també una mica de menjar del que tingués preparat a casa, perquè tenia molta fam. En un tres i no res, els àngels es presentaren davant santa Maria i li transmeteren les paraules del seu fill. De seguida, la Verge preparà un humil àpat, els el lliurà i els demanà que, en acabat, li portaren les sobres, amb les quals dinaria ella; i així s'esdevingué. Llegim com expliquen aquest passatge les diferents redaccions que hem pres en consideració una mica més amunt:

\section{Sermons, CLXI}

Mas quan Jesuchrist hac haüda victòria, llavors los àngels vingueren, axí com diu lo tema: «Ecce angeli accesserunt et ministrabant ei» (Ferrer 1975-1988: $\mathrm{V}, 135)$.

\section{Sermons de Quaresma, VIII}

E serviren-lo. De què? De dinar de vianda. E lo senyor Jesús trameté'ls a sa mare; e ells li porten noves que havia haguda victòria e havia fam, e la Verge Maria aparellà tost uns pocs de brots e sardina e vi, e los angels lo hi portaren, e dinà's; e puis los àngels tornaren ço que li sobrà a la Verge Maria, e, llavors, la beneita menjà e se dinà, e axí «angeli accesserunt laudantes Deum» (Ferrer 1977: I, 94).

\section{Ed. Colònia}

Et tunc dicit thema de Christo: «Accesserunt angeli», etc. Sed in quo ministraverunt ei? Nota quomodo illud quo Christus magis indigebat erat cibus, ideo ei in hoc angeli ministraverunt. Dicunt hic aliqui devoti contemplativi, quod sancti angeli iverunt subito ad Virginem Mariam, que nesciebat aliquid de Filio suo, nec ubi esset, qui sibi dicebant prelium et victoriam; que, auditis rumoribus victorie per dictos Angelos, misit sibi prandium, quod pro se paraverat, ut caules, vel brodium, vel spinargia, et forte sardineta, rogans angelos, ut quod sibi supererat, vel superesset, ad ipsam reducerent ad prandium (Ferrer 1485: s.f.).

\section{Ms. d'Aiora}

Et portaverunt de viatico, quod paraverat Virgo Maria (Ferrer 1995: 53-54). 
Resulta un fet destacable que la composició del menú que els àngels van presentar a Jesucrist varia segons la versió que llegim: així, deixant de banda els textos núms. 1 i 4, que no precisen res sobre el particular, ens trobem que, segons el núm. 2, va consistir en «uns pocs de brots, e sardina e vi», mentre que al núm. 3 es parla de «caules, vel brodium, vel spinargia, et forte sardineta» (resulta cridanera la presència del diminutiu valencià en el text llatí, que és clarament una recialla de l'oralitat primigènia del sermó). És igualment interessant constatar que, en aquesta mateixa versió, sant Vicent explicita quines són les fonts en què es basa la seua reconstrucció d'aquest àpat del Senyor: «Dicunt hic aliqui devoti contemplativi». Qui eren aquests devots contemplatius? Com hom ha posat de manifest agudament, el dominic sembla remetre ací a uns models que provenien en essència de la tradició franciscana: em referesc a les Meditationes Vitae Christi, atribuïdes durant molt de temps a sant Bonaventura de Bagnoregio, un text fonamental de l'espiritualitat medieval, a partir del qual es configurà la tradició de les Vitae Christi o Vides de Jesucrist escrites durant els segles XIV i XV. ${ }^{10}$

Les Meditationes - i el corrent d'obres que en deriven - pretenien suscitar en el lector una contemplació tan intensa que el fes submergir-se espiritualment en els diferents episodis de la vida de Crist. Amb aquesta finalitat, l'ànima devota - l'epítet amb què tant les Meditationes com les Vitae Christi solien adreçar-se al seu lector - era convidada tot sovint al llarg de l'obra a recrear mentalment, amb tot luxe de detalls, una determinada escena evangèlica, emplenant amb l'ajuda de la imaginació els silencis dels textos sagrats. Així, per exemple, el passatge de sant Mateu que ens ocupa és certament lacònic: només se'ns diu que «vingueren els àngels i serviren Jesús», però ja no se'ns donen més detalls. Doncs bé: d'acord amb les Meditationes, era del tot legítim que, dut per la seua devoció, el cristià medités sobre aquests esdeveniments tot subsanant segons el seu criteri aquesta llacuna de contingut. El contemplatiu disposava, per tant, d'un marge de llibertat molt generós a l'hora d'afigurar-se l'escena en la seua ment, la qual cosa implicava, naturalment, que la meditació sobre un mateix episodi podia donar lloc a resultats ben diferents segons qui medités: tants caps, tants barrets. A tall d'exemple, i si se'm permet un petit intermezzo gastronòmic, paga la pena de llegir com plasmen l'escena del servei dels àngels les Meditationes i els tres principals exponents de la tradició de les Vitae Christi a les nostres lletres medievals: la Vida de Jesucrist de Francesc Eiximenis, la Vita Christi de sor Isabel de Villena i el llibre Primer de Lo Cartoixà de Joan Roís de Corella, una traducció — de vegades molt lliure- de la Vita Iesu Christi del cartoixà germànic Ludolf de Saxònia:

Tunc duo ex ipsis pergentes in momento fuerunt cum ea, et eam reverenter salutantes, ambasiatam faciunt, et modicum pulmentum, quod sibi et Joseph paraverat, et panem cum tobalia et aliis opportunis portant; et forte Domina etiam aliquos pisciculos, si potuit, procuravit. Reversi ergo portant in plana terra, et mensas benedictionem solemniter peragunt. Conspice autem eum hic

10 Vegeu, sobre aquest punt, el treball de Hauf (2007), on es fa qüestió precisament de l'episodi de les tres temptacions al desert. 
bene in singulis quae agit. Sedet enim in terra composite ac curialiter, et sobrie comedit. Circumstant Angeli ministrantes Domino suo. Alius servit ei de pane, alius de vino, alius parat pisciculos, et alii cantant de canticis Sion, et jucundantur, et idem festum agunt coram eo (Meditationes Vitae Christi, cap. 17; Peltier (ed.) 1864-1871: XII, 540).

Tantost com lo Salvador hac haguda victòria en les dites temptacions, los sants àngels foren aquí ab ell, ministrant e servint-lo, satisfaent a la sua necessitat e fam ab gran diligència e ab sobirana reverència. La manera posa dominus frater Bonaventura en lo Libre de la vida de Jhesuchrist, dient que la gloriosa mare sua tot ço que dit és sabia per revelació, e per special gràcia li apparellà en un paneret que y posà un poquet de peix fregit, e aquí posà una tovalleta $\mathrm{ab}$ un petit tovallonet e posà aquí pa e sal e una ampolleta de vi, e l'àngel de Déu portà-ho al Senyor al desert e-ls altres àngels pararen-li la taula sobre una d'aquelles pedres planes que eren aquí, e.l Senyor féu lo vers ab los àngels e benehí la taula, lavades les mans, e assech-se en terra plegat e la un àngel lo serveix de trencar lo pa, l'altre de sal, l'altre de beure, l'altre li adobava lo peix separant-ne les espines (Vida de Jesucrist, 1l. VI, cap. 15; València, Biblioteca Històrica, ms. 209, f. 175vb).

E la Senyora, oint açò ab grans llàgrimes de grandíssima pietat e amor, desijosa de prestament servir lo seu amat fill, pres una cistelleta, e de ses pròpries mans posà en aquella unes tovalletes e un torcaboca, e tovallola d'eixugar les mans, e pa e fruita seca, e un poc de peix, car altra vianda no es trobava en casa sua; e açò donà ab infinit plaer al missatger que ho portàs al Senyor fill seu (Vita Christi, cap. 109; Villena 1995: 201).

Pres hun tabach la solícita verge Mare, y ab unes pobres netes tovalles lo dinar del Fill ordena. No s'oblida posar-y una tarraça y pregar los àngels que de la font de Jericó porten a son Fill ayga (Primer de Lo Cartoixà, cap. 23; Garcia (ed.) 2015: 447-448).

Hom pot advertir que segons les Meditationes el menú constava de pa i alguns peixets, que foren preparats davant Jesús mateix per un dels àngels mentre l'altre li servia el vi; d'acord amb la Vida de Jesucrist d'Eiximenis, el peix, ja fregit prèviament per la Mare de Déu, s'acompanyava de pa, sal i una ampolleta de vi; sor Isabel ens parla d'un poc de peix, pa i fruita seca; i Corella no especifica res sobre les menges que hi havia al tabac o panereta que santa Maria va preparar per al seu fill, però explica que lliurà als àngels una terrassa ('gerreta de boca ampla', DCVB, s.v. terrassa, acc. 1) i els ordenà que abans de tornar davant Jesús passaren per la font de Jericó per a omplir-la d'aigua. Convindrem, en definitiva, que de totes les versions reproduïdes la més nutritiva (si tenim en compte la possible presència dels espinacs en el menú) és la de la redacció llatina del sermó vicentí!

La imatge de Jesucrist com a cavaller apareix en d'altres llocs de la predicació vicentina. Un d'ells és el sermó per al primer diumenge després de Pasqua, bastit sobre el tema de Lc 24,40 («Ostendit eis manus et latus»), passatge en què l'Evangeli explica com Jesús, ja ressuscitat, s'aparegué als seus deixebles dins el cenacle de Jerusalem i els mostrà les nafres rebudes durant la cruci- 
fixió. En aquesta peça, el dominicà explica les raons per les quals el Fill de Déu volgué conservar aquestes cicatrius al seu cos, i ho fa al-ludint a la història d'un valent cavaller que reconquerí per al seu rei una ciutat rebel. El cavaller en qüestió rebé moltes ferides durant l'assalt a la plaça, ço que motivà que, en retornar victoriós davant el monarca, s'hagués de posar en mans dels metges. Aquests li asseguraren que no sols el podien guarir completament de les nafres rebudes, sinó que, a més, podien eliminar del seu cos qualsevol vestigi de les cicatrius produïdes per aquelles. Tanmateix, el cavaller els ordenà ben expressament que tinguessen bona cura de les ferides, però que respectessen les cicatrius, que volia conservar en record de les proeses que havia dut a terme. Naturalment, tota la història enclou un significat profund: la ciutat representa la humanitat, que es rebel-là contra el seu rei, Déu, i caigué en les urpes del diable; el cavaller, Jesucrist, que per tal de reconquerir-la hagué de suportar grans turments i, havent obtingut el triomf, no volgué delir del seu cos les nafres sofertes durant la Passió. Llegim-la en les seues redaccions catalana i llatina, ${ }^{11}$ entre les quals hi ha, de nou, algunes diferències interessants:

\section{Sermons, CLXXXVI}

La terça rahó per què Jesuchrist volch retenir les sues plagues fo per exalçar sa Passió virtuosa, e açò contra lo dimoni. E açò vos declararé per una semblança. Sapiau que una vegada fo una ciutat, e va's rebel.lar al rey, e hun cavaller dix al rey: "Senyor, donau-me companya, que yo la us hauré". Finaliter ell combaté la ciutat e fo ben nafrat, mas finalment ell la prengué; e depuix hagué metges que.l guarissen de les plagues, axí que ell los dix que.l curassen bé, mas volia que-ls senyals hi romanguessen per ço que-ls pogués mostrar al rey. Veus que aquesta ciutat és lo humanal llinatge, e los enemichs són los dyables, e lo cavaller fo Jesuchrist. E veus que batallà contra los dimonis e hac-ne victòria $\mathrm{e}$ romàs plagat e volch-se retenir les plagues (Ferrer 1975-1988: VI, 29-30).

\section{Ed. Colònia}

Tercia ratio est propter commendationem victorie de bello, quod habuit in die veneris sancta. Vult enim ut tantum negocium non tratadur oblivioni, ideo retinuit signa plagarum. Hoc potest declarari per parabolam de nobili civitate $a b$ infidelibus inimicis obsessa crudeliter, ita ut nullum recipiebant nisi ad mortem. Sed venit nobilis fortis miles et valens, qui pro liberatione bellavit cum inimicis, et finaliter habuit victoriam, sed fuit in praelio graviter vulneratus. Rex autem civitatis habuit peritissimum medicum, qui poterat ipsum totaliter curare, ne in eo apparerent signa plagarum, sed miles noluit, immo voluit ut taliter curaretur, ut remanerent signa plagarum ad commendationem victorie. Hec magna et nobilis civitas est natura humana, que fit ab illo magno principe Lucifero obsessa ultra V milia annorum, scilicet ab Adam usque ad Christum, intantum ut neminem recipiebat captivum, sed omnes ducebantur ad mortem in infernum, nec poterant habere remedium. Sed venit ille nobilis miles filius Virginis Marie armatus omnibus petris, ut posset recipere ictus, quia in sua divinitate non poterat pati, et in die veneris sancta intravit prelium contra

11 Vegeu l'inventari complet de les redaccions d'aquest sermó a Perarnau (1999: 704-705). 
Luciferum, et finaliter liberavit civitatem, sed fuit graviter vulneratus per totum corpus. Rex autem, id est Deus Pater, poterat ipsum taliter curare, ut nullum signum remaneret in suo corpore, sed Christus voluit retinere signa quinque plagarum principalium in signum et commendationem victorie (Ferrer 1485: s.f.).

Notem que, si bé tant el text núm. 1 com el núm. 2 representen l' «humanal llinatge» (és a dir, la natura humana) com una ciutat, en el primer cas es tracta d'una ciutat rebel-lada contra el seu senyor legítim (ço és, Déu), cal suposar que a causa del pecat original, i que ha estat reconquerida pel cavaller Jesucrist; en el segon, en canvi, es tracta d'una ciutat durament assetjada pels seus enemics (els dimonis) durant més de cinc mil anys, que finalment ha estat alliberada gràcies a la intervenció redemptora del Messies.

Cal notar, d'altra banda, que la similitudo proposada pel predicador respon a un topos d'ascendència patrística, en darrera instància. Així, Beda el Venerable (In evangelium Lucae expositio, 6, 24), tot just en glossar el passatge de l'aparició de Jesús als deixebles i els mots que donen peu al sermó vicentí («Ostendit eis manus et latus»), ja recull mutatis mutandis la història del guerrer que demana al metge que el cure, però de tal manera que les cicatrius de les ferides sofertes durant el combat resten al cos com a testimoni del seu valor:

Veluti similes aliquis fortissimus, iubente suo Rege, pro totius gentis salute singulari certamine desudans, multis quidem vulneribus exceptis, hostem tamen interficiat, spolia eius diripiat, victoriam suae genti reportet; et interrogatus a medico, cui curandus committitur, ita ne velit curari ut nec vestigia vulnerum ulla resideant, an magis ita ut cicatrices quidem remaneant, deformitas vero prorsus omnis et feditas absit, respondeat se potius ita velle sanari $u t$, toto salutis decorisque pristini statu recuperato, perpetua secum tanti circumferat signa triumphi. Sic profecto Dominus perpetis ob signum victoriae non excepta pro nobis vulnera passionis, sed ipsorum cicatrices coelo inferre quam abolere maluit (PL 92, cols. 630-631).

Resulten remarcables els motius pels quals l'heroi al-ludit per sant Vicent vol conservar les seues marques de guerra: «volia que-ls senyals hi romanguessen per ço que-ls pogués mostrar al rey». Si no vaig errat, són unes paraules mitjançant les quals el valencià lliga la història d'aquest guerrer desconegut amb la d'un famós general de l'Antiguitat de qui, precisament, es parla quasibé tot seguit al sermó: es tracta d'Antípater l'Idumeu, governador de Judea que va servir els romans Gneu Pompeu i Gai Juli Cèsar, i pare del rei Herodes el Gran que, segons el Nou Testament, ordenà la massacre dels Innocents. L'anècdota que sobre aquest personatge ens interessa ara fou recollida originalment per l'historiador jueu Flavi Josep (De bello judaico, 11. I, cap. 10; Josep 1956: II, 91-93), i d'ací passà a un dels compendis historiogràfics més cèlebres de l'Edat Mitjana: la Historia Scholastica de Pere Comèstor, conegut amb el sobrenom de Magister Historiarum, obra de referència per a teòlegs, comentaristes bíblics i també predicadors (Historia Libri II Machabaeorum, cap. 14; PL 198, col. 1531). De fet, la redacció valenciana cita el llibre de Comèstor, «lo Mestre de 
les Ystòries Scolàstiques», com a font; per contra, la llatina al-ludeix a una «hystoriam quam recitat Iosephus» (la confrontació d'ambdues redaccions permet, d'altra banda, constatar un error d'identificació clamorós en el text valencià, imputable, potser, a qui transcriví originalment el sermó pronunciat per mestre Vicent: parla, en efecte, d'un Antípater «que fo pare del rey Alexandre»; com és sabut, el pare d'Alexandre Magne fou el rei Filip II, tot i que és cert que ambdós monarques macedonis tingueren al seu servei un general anomenat, precisament, Antípater, que no té res a veure, però, amb el que protagonitza l'episodi del qual es parla al sermó).

En qualsevol cas, l'anècdota en qüestió es pot resumir així: Antípater, després d'haver servit llargament i de manera destacada els romans en el camp de batalla, fou acusat de traïció per alguns maldients envejosos davant Juli Cèsar. En assabentar-se de les greus acusacions, el jueu decidí de comparéixer motu proprio a la cort del general romà, i llavors, a la vista de tothom, es va despullar de les vestidures que portava, oferint als presents la visió del seu cos, ple de les nafres que havia rebut combatent al servei de Roma. Antípater rematà aquella exhibició amb una frase lapidària: en comptes de defensar la seua innocència amb un llarg discurs, havia decidit que foren aquelles cicatrius les que parlaren en favor seu. Impressionat pel capteniment d'aquell guerrer, Cèsar el donà per lleial i castigà aquells que n'havien malparlat:

\section{Sermons, CLXXXVI}

Mas per bé entendre açò, dir-vos he una bella ystòria que recite lo Mestre de les Ystòries Scolàstiques de aquell Antípater que fo pare del rey Alexandre. Veus que aquell havia haüd grans batalles contra los enemichs, e depuix per envega acusaren-lo ab l'emperador, e l'emperador féu-lo's venir davant e dixli: «Diu-se que tu me vols fer traÿció». «Yo?», dix aquest. Diu que va.s despullar tot nии davant l'emperador e mostrà-li los colps que havie rebuds, dient: «Senyor, aquest colp, per amor de qui.l rebí? E aquest?», etc. «No.ls rebí per amor de vós?». «Sí». «E donchs, ¿com podeu pensar que yo volgués fer trä̈ció en vostra casa? Ans, senyor, quan yo hagués fet algun defalliment en vostra casa, per amor de aquests colps vós me deuríeu perdonar». E llavors l'emperador llevà's e abraçà'l e besà'l, dient: «Yo te perdó», e puní aquells qui l'havien acusat.

Semblantment féu Jesuchrist, que quan les querelles van a Déu per los dimonis, dient: «Los vostres servidors fan tants de peccats e no se'n volen estar. Axí mata'Is!», veus que Jesuchrist diu a Déu lo Pare: «Senyor, guardau: per qui he pres yo aquests colps e aquestes plagues? Senyor, per la vostra amor. E axí hajau hic misericòrdia, que yo·y trametré prëycadors e faran penitència» (Ferrer 1975-1988: VI, 30).

\section{Ed. Colònia}

Ad declarandum modum huius interpellationis, notavi hystoriam quam recitat Iosephus de Antipatre patre Herodis Ascolonite, qui occidit innocentes, qui pro imperatore fuit vulneratus in multis preliis, qui fuit ab invidis accusatus apud imperatorem de proditione. Et citatus ab imperatore comparuit et respondit, non verbo, sed facto, quia nudatus ostendit vulnera imperatori dicens: 
«Non sunt ista signa proditionis, sed fidelitatis». Tunc amplexatus est eum imperator et osculatus. Sic miles Christus pro honore Dei Patris bellavit. Et in domo Christi, scilicet Ecclesia, et in genere suo, scilicet humano, fiunt multa mala et proditiones contra Deum Patrem recurrendo ad divinos, inimicos Dei, etc. Et clamores, querimonie et accusationes veniunt cotidie coram Deo Patre, qui dicit Filio: «Fili, in domo vestra sustinetis vos proditiones contra me», etc. Christus respondet Patri ostendendo vulnera, dicens: «Et quare recepi ego ista vulnera? Nunquid ut expectetis eos ad poenitentiam?» (Ferrer 1485: s.f.).

Tot seguit, fra Vicent ens dóna les claus per a entendre la similitudo entre Antípater i Jesucrist: igual com el primer mostrà les seues nafres a Cèsar per a desmentir els rumors que circulaven sobre la seua traïció, el segon, al cel, fa el mateix davant el Pare quan aquest li retreu les traïcions que cometen contra Déu els homes a la terra (es tracta, òbviament, dels pecats mortals, entre els quals la versió llatina en llista un de molt d'específic: el que fan aquells que recorren a endevins, enemics de Déu). El Pare, en efecte, està irat amb la humanitat, però el Fill demana clemència per a nosaltres i aconsegueix d'aplacar-lo, mostrant-li les nafres que, com a obedient fill, rebé en el seu cos per a redimir-nos. En aquest sentit, convé tenir en compte que l'associació entre Antípater i Jesucrist és un lloc comú de la tipologia cristiana, és a dir, el sistema d'interpretació de la Bíblia que veia en els personatges i els fets de l'Antic Testament prefiguracions dels del Nou. Basta citar l'exemple de l'Speculum Humanae Salvationis, una de les obres tipològiques més conegudes del període medieval:

\footnotetext{
Sicut enim Christus descendit propter nos de coelo usque ad infernum, Ita reascendit in coelum, ut exoret pro nobis usque ad sempiternum; et ideo, si peccavimus, desperare non debemus, quia fidelem advocatum apud Deum nos habemus. Quod autem Christus vulnerum cicatrices Patri monstrare volebat, hoc etiam olim per quandam figuram ostensum erat. Antipater, miles strenuus, delatus fuit imperatori Julio, quod infidelis et inutilis miles fuisset Romano imperio quapropter ille, se exuens, nudus coram imperatore assistebat Et ei cicatrices vulnerum suorum coram omnibus ostendebat, dixitque non esse opus se verbis expurgare, cum cicatrices viderentur ejus fidelitatem acclamare; quod videns, Caesar ejus excusationem approbabat et eum fidelem et strenuum militem affirmabat.

Pulchre Christus praefiguratus fuit per istum Antipatrem, quia ipse semper pro nobis stat ante suum Patrem, et cicatricibus suis ostendit se militem strenuum fuisse et mandatum Patris ejus tanquam fidelis miles complevisse; quapropter Deus tam fidelem militem non cessat honorare, et quodcunque petierit, paratus est sibi dare (cap. 39, vv. 5-24; Lutz — Perdrizet (ed.) 1907: I, 80).
}

I en els versos següents, l'Speculum explica que Jesucrist rebé l'ordre de cavalleria segons l'ús germànic («more Alamannico»), d'acord amb el qual el 
guerrer rebia una bescollada ritual en el moment de ser armat cavaller novell. El Senyor, però, no rebé una única bescollada, sinó moltes, les que li donaren els seus captors; la seua cavalcadura no fou cap destrer de batalla, sinó l'ase sobre el qual entrà a Jerusalem el Diumenge de Rams; el camp on batallà, el Calvari; la seua llança, aquella amb què el romà Llongí el ferí a la creu; el seu elm, la corona d'espines punxegudes; i la cimera o ornament de l'elm, el títol de la creu; etc. ${ }^{12}$

\section{III.- BATALLA CAMPAL: ELS EXÈRCITS DEL BÉ I DEL MAL}

Si fins ara hem vist la pugna contra Llucifer i les seues temptacions plantejada com una justa cavalleresca que acaba amb el triomf del campió Jesucrist, en els exemples que analitzarem a continuació ens trobarem el conflicte entre els vicis i les virtuts expressat en els termes d'un combat a camp obert lliurat entre dos grans exèrcits: el del conjunt dels cristians, d'una banda, i el del diable i els seus capitans, de l'altra. Un exemple ben clar d'aquest tractament és el sermó predicat a València el 26 de març de 1413, tercer diumenge de Quaresma, contingut als anomenats Sermons de Quaresma (XXII), conservats al ms. 273 de l'Arxiu de la Catedral de València. El tema d'aquesta peça és la breu paràbola del guerrer fort explicada per Jesucrist a Lc 11,21 («Fortis armatus custodit atrium suum»), paràbola que concorda perfectament amb el desenvolupament que sant Vicent donarà a la seua prèdica, dedicada a «la batalla campal e general que en aquest temps de Quaresma ha lo poble cristià contra los dimonis» (Ferrer 1977: I, 179). En efecte, la idea que s'enuncia a l'inici d'aquest sermó — després de l'enunciació del tema i de la preceptiva invocació a la Verge- és que, durant la Quaresma, el món es converteix en un immens camp de batalla, i que en aquest camp els cristians són una host en formació de combat que, practicant l'abstinència, ha de fer front al poderós assalt dels diables:

Vosaltres devets pensar que en temps de Quaresma és així com un camp de batalla, en la qual tot lo poble cristià fa batalla general contra los dimonis, car, en altre temps del any, bé són molts devots que tots temps estan en batalla contra los dimonis e pecats e temptacions; mas aquelles són persones poques. Emperò ara en Quaresma és la batalla de tot lo poble cristià contra dimonis (ibidem). ${ }^{13}$

12 «Miles iste, id est Christus, factus fuit more Alamannico, / ubi in creatione militis solet dari ictus in collo; / sed miles iste, Christus, non suscepit tantum colaphum unum, / sed colaphorum et alaparum quasi infinitum numerum. / Dextrarius ejus erat asinus, cui insedit in die Palmarum; / campus praelii, in quo pugnabat, erat mons Calvariarum; / hasta ejus fuit Longini militis lancea; / corona de acutissimis spinis erat sibi pro galea; / signum sive ornamentum galeae fuit tabula tituli» (cap. 39, vv. 35-43; Lutz - Perdrizet (ed.) 1907: I, 80).

13 Una idea ben similar es retroba, per exemple, en el sermó per al tercer diumenge de Quaresma conservat al ms. 476 de la Biblioteca de Catalunya: «aquest temps de la Coresma és temps en lo qual los demonis fan major batalla que en altre temps de l'anyn. E és la rahó aquesta: car tot l'altre temps les gens fan ço que lo demoni vol, e la sua voluntat; e axí, pus fan la sua voluntat, no·ls pugna [...] Mas ara, en aquest temps, cascú se esforsa de tornar-se a Déu per 
Que les temptacions amb què el diable pretén de causar la perdició dels homes són especialment intenses durant la Quaresma és quelcom que s'afirma també a la Summa Praedicantium (s.v. bellum) del frare dominicà anglés John Bromyard, un text d'una importància molt notable en la història de la predicació medieval, atés que oferia pautes i models per a l'elaboració de sermons. ${ }^{14}$ Com sant Vicent, en aquesta obra Bromyard compara les temptacions quaresmals amb una guerra entre els creients i les forces del mal: en efecte, afirma que, en arribar aquesta època de l'any, el diable prepara contra Déu i els seus fidels un gran exèrcit. No es tracta, però, en aquest cas d'un exèrcit de diables, sinó més aviat de servents del diable, pecadors i pecadores de vida dissoluta, poc donats als sacrificis propis de la Quaresma. Bromyard es queixa amargament de la facilitat amb què aquesta tropa deshonesta ha aconseguit de sumar a les seues files molts homes aparentment rectes i devots, i ho fa plantejant una hipòtesi que, vista des de la perspectiva d'un lector actual, si més no, resulta involuntàriament humorística: si la host del Crist al complet (apòstols, sants i màrtirs) s'aparegués un dia a la ciutat i la recorregués predicant a la gent sobre el cel, i de sobte passés pel mateix lloc una processó de meretrius abillades deshonestament, aquestes seduirien molts més ulls, orelles i cors que els primers:

Isto tempore diabolus parat fortissime exercitum suum contra eum in choreis et spectaculis. Adducens milites et militissas suas, in quolibet peccato armatos, habentes pro galea cornua, et capitegia, et frontalia. Et sic de alia armatura, in tantum quod a planta pedis, usque ad verticem capitis, nihil in eis invenies, nisi sagittas diaboli acutissimas, non enim est in eis animae sanitas (Esaiae I). Quia in omni parte corporis et capitis et pedis nihil aliud in eis invenies, nisi sagittas diaboli acutissimas ad vulnerandum cor intuentis, nec deest eis tympanum pro buccina, nec tuba ad buccinandum ad bellum. Heu! Isti sunt dispositi multo fortius et diligentius, et cum maiori et ferventiori voluntate, et laetitia contra Deum et suos, quam videam multos Christi milites pugnare contra diabolum et eius ministros, et plures ad se convertunt, quia si omnes Christi milites totiusque eius exercitus, videlicet Apostoli et martyres, atque omnes sancti viri in forma in qua fuerunt in ecclesia, irent per civitatem Dei praecepta praecipiendo vel praedicando pro Deo pugnaturi, et irent in alia processione mulieres in habitu meretricio ludentes, seu coreizantes, vel cum signis levibus incedentes, credo esse certus, quod iste multo plura corda et aures et oculos libentius et intensius post se inclinarent, quam illi, nec tot pro istis peccare cessarent (Bromyard 1586: I, 93d).

Ben mirat, si analitzem el desenvolupament del sermó vicentí, veurem que des del punt de vista estructural respon a una tipologia que hom ha sabut detectar en diversos exponents de la producció sermonària del dominic valencià, en què tota la prèdica es pot entendre com una gran similitudo, o, si més no, com

penitència e confessió, restitució e contricció. E aquest, vehent açò, mou més guerra e pus fort» (Perarnau 1996: 165).

${ }^{14}$ Sobre la figura de Bromyard i el context històric i cultural en què la Summa s'inscriu, vegeu els treballs de Boyle (1973) i Binkley (1995). 
el desenvolupament o l'explanació detallada d'una similitudo que ha estat plantejada a l'inici de la peça. ${ }^{15}$ En el cas que ens ocupa, ja ho hem vist, aquesta similitudo és Quaresma = camp de batalla; si desenvolupem aquesta imatge, caldrà veure, en primer lloc, amb quines armes podrà el cristià combatre i sobreviure en aquest camp tan perillós. Es tracta, òbviament, d'unes armes allegòriques, espirituals, del mateix estil de les que podem trobar al Llibre de l'orde de cavalleria de Ramon Llull o el poema L'arnés del cavaller de Pere March, obres on les diferents peces de l'armadura del guerrer representen les virtuts que aquest ha de tenir. A parer de sant Vicent, que en aquest punt cita tot just el passatge de la Carta als Efesis ja més amunt al-ludit, aquesta armadura —una armadura de «penitència bona e devota» (Ferrer 1977: I, 179)— es concreta en tres peces, dues de defensives i una tercera d'ofensiva: a) en primer lloc, l'escut, que representa el dejuni i l'aflicció corporal; b) en segon lloc, la cervellera o capellina de ferro, que representa l'oració; c) en tercer lloc, la llança, que representa la confessió, «car la confessió és llançada» que el cristià «dóna al diable» (ibidem). Guarnits amb aquesta armadura espiritual, els creients podran fer front als diables i defensar amb èxit la seua casa, és a dir, la seua ànima, una afirmació que demostra la veracitat del tema del sermó («Açò diu lo tema: "Fortis armatus custodit atrium suum"; lo poble cristià, armat de la fe catòlica en les dites maneres, porà entrar en la batalla contra lo diable», Ferrer 1977: I, 180).

Introduit i justificat el tema, arribem a la part que, des del punt de vista de l'estructura del sermó i del desplegament dels continguts que s'hi abordaran, constitueix la clau de volta de tot el text. Els manuals medievals de predicació solen referir-s'hi amb el nom de divisio thematis: es tracta d'un mecanisme que permet al sermonador de descompondre o subdividir el tema general en apartats més concrets i acotats. El que resulta significatiu en el cas que ens ocupa és que, de manera ben conseqüent amb el caràcter bèl-lic de la similitudo plantejada a l'inici, per tal de dur a terme aquesta divisió sant Vicent declara obertament haver-se inspirat en un ben conegut tractat dedicat a l'art de la guerra: el De re militari de Flavi Vegeci Renat, escriptor romà del segle IV l'obra del qual va gaudir d'una considerable difusió durant els segles medievals. ${ }^{16} \mathrm{Si}$, en efecte, llegim com resolen el passatge de la divisio thematis les principals redaccions que es conserven d'aquest sermó, ${ }^{17}$ podrem constatar el recurs a aquesta auctoritas per part del valencià:

\section{Sermons, CLXXIII}

E per ço com aquest tema parle de batalla, yo, conformant-me ab la Església, posar-vos-ó he en pràctica, ut dicit Egidius, com la guerra deu haver set condicions, ut sequitur: la primera, corredors descobrints;

15 Ysern (2015: 71) assenyala que «estrictamente hablando, todo un sermón puede constituirse como una auténtica similitudo», en el si de la qual és possible de trobar exempla i desenvolupaments al-legòrics de vegades notablement sofisticats.

16 Vegeu Allmand (2011) quant a la fortuna de Vegeci durant l'Edat Mitjana, i el treball de Badia (1984), referit a la seua presència en les lletres catalanes dels segles XIV i XV.

17 Vegeu el catàleg de Perarnau (1999: 605-606). 
la 2a, ballesters sagetants;

la $3 \mathrm{a}$, botziners provocans;

la $4 \mathrm{a}$, penoners designans;

la $\mathrm{V}^{\mathrm{o}}$, cavallers militans;

la $\mathrm{VI}^{\mathrm{a}}$, hòmens pedissicans;

la VII', adzemblers confortans (Ferrer 1975-1988: V, 204).

\section{Sermons de Quaresma, XXII}

Jo, pensant com vos poria declarar esta batalla, he trobat, De re militari, que en batalla de rei són set diferències de gents, així com trobarem en esta batalla:

[1. Algarers]

[2. Ballesters]

[3.Nafils, trompetes]

[4. Penoners]

[5. Hòmens

de cavall]

[6. Peons]

[7. Reqüers

o atzembles]

(Ferrer 1977: I, 180).

\section{Ed. Colònia}

Cogitanti mihi quomodo possem vobis hoc bellum declarare occurrit mihi motivum Vegecii, De re militari, qui dicit quod in bello regali bene ordinato et regulato sunt septem differentie pugnatorum, scilicet exploratores, balistarii, tubicine, vexilliferi,

equestres, pedestres

et vectores.

Omnes istas septem differentias pugnatorum invenio in bello populi christiani, cuius caput est rex Christus, contra demones, quorum rex est Lucifer (Ferrer 1485: s.f.).

\section{Ms. d'Aiora}

Nunc declarato themate, videatis quomodo in hoc prelio totus populus christianus existit, et ideo videamus de ordinacione istius belli. Et inveni, secundum quod declarat Vegecius, De re militari, quod septem sunt necessaria in prelio, que hic omnia comperio et sunt hec que debet habere omne prelium regale, vel magni Principis.

Et primo Algarés, Ballestés,

Naffilés,

Penonés,

Cavallers,

Peons

et Reqüers (Ferrer 1995: 216).

\section{Ms. de Perugia}

Nota ergo in exercitu christiano, nunc fortiter armato contra demones, differentias pugnatorum, ad modum regii exercitus: 
Cursarii explorantes;
Ballistarii sagitantes;
Tubicinarii proclamantes;
Vexillarii designantes;
Equitarii penetrantes;
Peditarii concertantes;
Saumatarii comportantes (Ferrer 2006: 192).

Notem que la comparació de les diferents versions deixa veure una curiosa divergència al text núm. 1 pel que fa a l'autoritat invocada per sant Vicent: en aquest cas, no es tracta de Vegeci, sinó d'un Egidius rere el qual cal veure la figura d'Egidi o Gil de Roma, autor del De regimine principum, un dels espills de prínceps més coneguts i llegits de l'Edat Mitjana, que, com Vegeci, també dedica certa atenció a qüestions de caire militar. En qualsevol cas, mitjançant el recurs a l'autoritat el nostre predicador identifica set tipus de tropes que es poden trobar en tot exèrcit. En la versió dels Sermons de Quaresma (núm. 2), igual que s'esdevé en les núms. 3 i 4, aquests set tipus de tropes són explicitats en forma d'una mera llista, però si observem les núms. 1 i 5 , ens trobarem amb una divisió rimada, segons l'ús més habitual de les artes praedicandi medievals: concretament, al núm. 1 cada substantiu (corredors, ballesters, botziners) va seguit d'un adjectiu, i són els adjectius — tret d'un cas- els que rimen entre ells (en -ants: sagetants, provocants, botzinants, etc.); al núm. 5 el fenomen és més sofisticat, perquè hi ha una doble rima: els substantius rimen en -arii (cursarii, ballistarii, tubicinarii), mentre que els adjectius ho fan en -antes (explorantes, sagitantes, proclamantes). Naturalment, el procediment facilitava la memorització per part del predicador de les categories que més tard hauria de desenvolupar al sermó.

Així doncs, la divisió en set distincions marca la pauta i el disseny de la prèdica, si tenim en compte que la tesi que sant Vicent desenvoluparà tot seguit és que, igual com s'esdevé en la guerra terrenal, en l'espiritual - la que lliura l'exèrcit dels cristians contra el diable i els pecats - també existeixen, a nivell simbòlic, aquestes set menes de combatents. En conseqüència, ens trobarem a partir d'ara set seccions, una per cada tipus de tropa dels que han estat assenyalats, al llarg de les quals glossarà quina és la funció d'aquests soldats dins la host i quin és el seu equivalent en el combat espiritual de la Quaresma. S'hi estableixen, doncs, una sèrie de correspondències al-legòriques, basades en paral-lelismes que de vegades resulten raonables i d'altres — des d'una òptica moderna, si més no- una mica agafats amb pinces. Així, els algarers (corredors o exploradors) són espiritualment parlant els contemplatius, perquè, igual com els primers exploren el territori i detecten possibles aguaits d'enemics, els segons, mitjançant la meditació, exploren amb la ment aspectes de la divinitat ignorats per la resta dels homes i coneixen millor els paranys que el diable sol parar als homes. Per contra, els ballesters, que castiguen l'enemic abans que s'arribe al cos a cos, són les persones actives, que disparen contra el diable fent obres de misericòrdia (cada obra de misericòrdia és, per tant, un virató —una sageta prima de fusta amb punta metàl-lica- que es llança contra el maligne. Hi ha, encara, un altre aspecte interessant sobre aquest paral-lelisme entre la 
ballesta i la misericòrdia, al qual em referiré una mica més avall). Els anafils o trompetes, que amb els seus tocs donen ordres o infonen ànims a l'exèrcit, són els predicadors, que des de la trona animen els cristians a combatre el mal, tot fent sonar les dues trompes d'argent de què disposen, que són els llibres del Vell i del Nou Testament. Els penoners o banderers són els penitents, que han deixat enrere els seus pecats (és a dir, han renunciat a la bandera de l'exèrcit del diable, en el qual militaven abans) i, redimits, han pres l'estendard de la penitència, que és, tot just, la bandera de l'exèrcit de Jesucrist. Els cavallers són els purs, els verges: el cavall representa la carn, i el genet que el cavalca l'esperit; els verges han sabut mantenir a ratlla els impulsos del seu cavall, i no han caigut, per tant, en el fang de la luxúria; d'aquests, però, n'hi ha ben pocs, ens adverteix el sant. La major part de l'exèrcit cristià milita en la infanteria, la peonada: els peons han conegut la carnalitat, de manera que han de lluitar amb els peus al fang, però tot i així tracten de dur una vida virtuosa. Finalment, els recuers o atzemblers, encarregats de transportar a la rereguarda tota la impedimenta (armes, vitualles, etc.), són els preveres, que subministren als guerrers de la host cristiana, quan tenen fam, l'aliment del cos de Jesucrist.

\section{SERMONS DE QUARESMA, XXII (FERRER I977: I, I80-I85)}

\begin{tabular}{|l|l|}
\hline \multicolumn{1}{|c|}{ Batalla terrenal } & \multicolumn{1}{|c|}{ Batalla espiritual } \\
\hline $\begin{array}{l}\text { Algarers (corredors, exploradors): «Són } \\
\text { genetaris per descobrir los aguaits dels } \\
\text { enemics, e aquells són llaugers, quasi } \\
\text { volants, van guardants deçà e dellà». }\end{array}$ & $\begin{array}{l}\text { Contemplatius: «aquests són persones } \\
\text { contemplatives, que ab lo ginet van } \\
\text { quasi volant e corrent per muntanyes, } \\
\text { descobrint los aguaits dels diables». }\end{array}$ \\
\hline $\begin{array}{l}\text { Ballesters: «en batalla campal e bé } \\
\text { ordenada, són mester ballesters, que ans } \\
\text { de la mescla damnifiquen los enemics». }\end{array}$ & $\begin{array}{l}\text { Actius en obres de misericòrdia: «Quals } \\
\text { són en esta batalla? Persones actives, } \\
\text { persones misericordioses. E com? Cada } \\
\text { almoina e cada obra de misericòrdia, } \\
\text { és virató que fer al diable, e així, en est } \\
\text { sagrat temps, los qui fan almoines han } \\
\text { ofici de ballesters». }\end{array}$ \\
\hline $\begin{array}{l}\text { Anafilers: «Trompetes molt necessàries } \\
\text { hi són [...] Sabeu per què? Lo crit de la } \\
\text { trompeta mou tots los coratges, e mou } \\
\text { la sang». }\end{array}$ & $\begin{array}{l}\text { Predicadors: «Quals són aquests? Los } \\
\text { preïcadors ab llur preïcació de trompa». }\end{array}$ \\
\hline $\begin{array}{l}\text { Penoners: «són mester penoners que } \\
\text { porten les banderes». }\end{array}$ & $\begin{array}{l}\text { Penitents: «Aquests són los penidents e } \\
\text { faents penitència: la bandera o penó de } \\
\text { Jesucrist en est món fon penitència. Los } \\
\text { qui deixen la bandera del diable e prenen } \\
\text { la de Jesucrist [...]». }\end{array}$ \\
\hline
\end{tabular}




\section{SERMONS DE QUARESMA, XXII (FERRER 1977: I, I80-185)}

\begin{tabular}{|l|l|}
\hline \multicolumn{1}{|c|}{ Batalla terrenal } & \multicolumn{1}{c|}{ Batalla espiritual } \\
\hline $\begin{array}{l}\text { Homes de cavall: «La cinquena cosa } \\
\text { necessària a la batalla és hòmens de } \\
\text { cavall». }\end{array}$ & $\begin{array}{l}\text { Verges: «són així persones vèrgens que } \\
\text { se són sabudes regir sobre lo cavall, que } \\
\text { no són caiguts en lo fang de luxúria. Lo } \\
\text { cors és cavall, l'esperit és lo cavaller } \\
{[\ldots] \text { Així com cavaller ha mester bon fre }} \\
\text { a la boca del cavall, així lo teu fre sia } \\
\text { abstinència de menjar e beure; si no, no } \\
\text { el poreu tenir, e gitar-vos-ha en lo fang } \\
\text { de luxúria». }\end{array}$ \\
\hline $\begin{array}{l}\text { Peons: «són los peons que van ab gran } \\
\text { treball carregats d'armes". }\end{array}$ & $\begin{array}{l}\text { Bons cristians que han pecat carnalment: } \\
\text { «són homens e dones continents, que no } \\
\text { són vèrgens, que són en matrimoni. Uns } \\
\text { han perduda la virginitat sens pecat en lo } \\
\text { matrimoni; altres l'han perduda ab pecat: } \\
\text { jamés no poden batallar a cavall, puix } \\
\text { són caiguts del cavall». }\end{array}$ \\
\hline $\begin{array}{l}\text { Recuers: «porten armadures, e vitualla, e } \\
\text { medecines». }\end{array}$ & $\begin{array}{l}\text { Preveres: «aquests són los qui han cura } \\
\text { d'ànimes, prelats, rectors, vicaris e altres } \\
\text { havents cura d'ànimes; perquè, si has } \\
\text { pecat, ha's trencat l'armadura, o trencat } \\
\text { lo dejuni, dar-li ha més armes. Si és } \\
\text { nafrat en pecat de supèrbia, dar-li-ha } \\
\text { estopada de humilitat; si de luxúria, } \\
\text { lavar-la ab vi e metre-hi oli, penitència } \\
\text { e almoines; e si és flac algú, dar-li ha } \\
\text { menjar aquella hòstia sagrada». }\end{array}$ \\
\hline
\end{tabular}

Fa mal de dir si, a l'hora de traçar aquest seguit de correspondències al-legòriques, sant Vicent va treballar a partir d'una única font on totes elles ja eren presents; sí que sabem, en canvi, que algunes són llocs comuns fàcilment retrobables en fonts patrístiques i teològiques medievals. La identificació dels anafils o trompetes amb els predicadors, per exemple, la fan autors com Alain de Lille («Tuba [...] dicitur manifesta praedicatio», Liber in distinctionibus dictionum theologicalium, s.v. tuba; PL 210, col. 981) o Honori d'Autun («Tubae sunt praedicatores», Expositio in Psalmos, 150, 6; PL 172, col. 308). Quant a l'associació entre cavallers i verges, que en darrera instància sembla basar-se en Ap 19, 14, on es parla del genet sense nom seguit pels exèrcits del cel, muntats sobre «equis albis» i vestits d'un lli blanquíssim, es pot llegir, ara com ara, en Ambròs Autpert (Expositio in Apocalypsin, 11. IX; Autpert 1536: 369), Haimó d'Halberstadt (Expositio in Apocalypsin, 11. VII, cap. 19; PL 117, col. 1175), Bruno de Segni (Expositio in Apocalypsim, 11. VI, cap. 19; PL 165, col. 710) o Hug de Saint Cher (Liber Apocalypsis, cap. 19, lletra l; Saint Cher 1703: VII, 419d).

Un altre aspecte destacable d'aquestes subdivisions és que algunes tenen una estructura complexa; vull dir que algunes enclouen en el seu interior d'altres 
subdivisions, en les quals hom es permet d'aprofundir encara més en l'al-legoria. Aquest és, per exemple, el cas de la subdivisió corresponent als ballesters, que adés havíem deixat pendent de comentari. En efecte, en associar aquests guerrers amb els qui fan obres de misericòrdia, ens explica també com és l'arma espiritual que fan servir: així, si la ballesta terrenal consta de tres parts principals - el lleny o arbrer, recte i de fusta, que presentava una ranura acanalada on es posava el projectil; l'arc, corbat i generalment d'acer trempat; la corda, que es tibava per tal de corbar encara més l'arc i donar la força necessària al tret-, en la ballesta dels misericordiosos trobem també aquestes mateixes parts: l'arbrer representa la intenció recta del cor, ja que les obres de misericòrdia (com ara l'almoina) s'han de fer perquè són justes, no pas per guanyar-se als ulls del món la fama de misericordiós; l'arc corbat significa la compassió envers el pobre i l'afligit, com quan l'home de vida pròspera encorba el cos per acostar-se més a aquell qui jau en la misèria i fer-li caritat; la corda que tiba l'arc és el manament de Déu sobre la misericòrdia a Mt 12, 7; quan aquestes tres parts de la ballesta espiritual funcionen com cal i el misericordiós fa la seua obra de misericòrdia, llança, com ha estat dit, un virató letal contra el dimoni:

la ballesta té lo arc tort e lo arbrer dret, e corda tibant: lo arbrer és la intenció dreta; guarda't que sia dreta la intenció a Deu [...] Item, lo arch tort és lo cors, que.s deu inclinar a haver compasió de son proïsme, pensant en les prosperitats que és, e en les misèries que és lo pobre [...] La corda tibant hi és mester, ço es, lo manament de Déu: «Misericordiam volo», diu Deu. E així, si haveu estes tres coses, metets-hi lo virató, e darà gran colp al diable, ab aquests passadors [un altre tipus de sageta molt aguda] encebats e encuixats [...] Diu lo malvat: «Heu michi, que nafrat só!» (Ferrer 1977: I, 181).

Convé assenyalar que, per bé que puga resultar cridanera, aquesta manera de concebre el sermó - tant pel que fa a la semblança emprada com a la disposició de la peça- no és original ni exclusiva de sant Vicent. Molts d'altres predicadors fan servir la imatge de l'exèrcit per referir-se a la manera com el conjunt de la cristiandat o, si més no, els creients virtuosos combaten contra les temptacions i tracten d'aconseguir la salvació de les seues ànimes. Fins i tot és possible de trobar alguns sermons que desenvolupen extensament la imatge esmentada i són bastits a partir de la descripció de l'ordre de batalla d'aquesta host espiritual. Aquest és, per exemple, el cas del sermó per al dijous després del segon diumenge de Quaresma de sant Bernardí de Siena, coetani de sant Vicent. De fet, si bé es mira, aquest text i el sermó vicentí sobre «Fortis armatus» presenten algunes similituds força interessants. Així, sant Bernardí distingeix a l'inici de la seua prèdica cinc tipus de tropes que es podien trobar als exèrcits dels antics. Els dos primers són els velites i els excubitores:

In exercitibus antiquorum, quinque manerierum militum ducebantur. Primo quidam vocabantur velites, qui erant iuvenes levis armaturae, quod hodie latini vocant valetos; isti erant agiles et primo movebant bellum.

Secundo erant excubitores, qui die et nocte custodiebant exercitum, inter se tamen divisi, ne nimis vigiliarum labore graverentur; maxime enim cura erat 
antiquitus, ut custodibus exercituum, tanquam eis uti sit valde necessarium: nam Frontinus recitat, propter hoc Claudius Imperator vicit Cimbros (Siena 1650: III, 93-94).

Vet ací un altre paral-lelisme interessant: si adés hem vist que, per tal de descriure les set esquadres de l'exèrcit espiritual, sant Vicent acudia a l'autoritat que en qüestions militars representava Vegeci, ací, a l'hora de ponderar el rol i la importància dels excubitores en la protecció dels campaments, sant Bernardí recorre a un exemplum històric extret d'una altra obra de referència sobre la mateixa matèria: els Strategemata (1l. II) de Sext Juli Frontí. Seguim llegint, però, el text de Bernardí, que es refereix ara als deservi, els alares i els vexillatores:

Tertio erant deservi, ut enim dicit Isidorus, quod nunquam servis promissum est ad militiam admicti, sed postquam Romani ab Annibale apud Cannas fuerunt devicti, ut perditam militiam recuperarent; omnes servos fecerunt liberos, et ita eis militare concessum est, unde tales milites dicebantur deservi, id est non servi, sed desinentes esse servi.

Quarto erant alaris, qui per modum alaris aciem protegebantur, et isti a tota acie erant separati, et inordinate habebant percutere hostes; discurrebant enim per campum, et illud divertebantur, et videbantur necessarium.

Quinto erant vexillatores, qui velis et flammis utebantur (Siena 1650: III, 94).

Tot seguit Bernardí explica el simbolisme d'aquestes categories de soldats: els velites, que són àgils perquè quasi no van armats, són els pobres de Déu, quasi desproveïts de béns terrenals, però que per això mateix són més a prop del regne del cel; els excubitores, sempre alerta, representen una condició indispensable dels vertaders atletes de Crist, que han d'evitar la peresa i restar sempre a l'aguait contra les escomeses del diable; els deservi, antics servents, són els antics pecadors, que han deixat la vida dissoluta que duien i ara han estat admesos entre els bons; els alares, que ajuden l'exèrcit quan cal, són els contemplatius, que ajuden l'ànima amb la lectura dels textos sagrats; i els vexillatores representen els qui fan obres de caritat, qualitat que és la bandera principal de la milícia divina:

Erant ex hoc ab omnibus aliis separationis, et sic patet, quod sunt quinque maneries militum spiritualiter loquendo, ita debet esse in bello spirituali, quia primo debent esse pauperes, per illos agiles et leves, qui non praemuntur gravitate terrenorum: sicut enim grave pondus impedit, volentem velociter currere, sic terrena omnia gravant Christi militem, qui cum diabolo vult pugnare [...]

Secundo sunt excubitores, id est stabiles, qui significantur per custodes: sicut enim illi, sic et Christi milites debent esse stabiles et non vagi [...]

Tertio penitentes, qui significantur pillos, qui servi fuerant, sed ulterius non erant; ita isti relictis peccatis, quorum praemebantur servitute admittuntur Christi militiae $[\ldots]$ 
Quarto sunt contemplativi, qui studio scripturarum insistunt, et figurantur per illos qui aciem protegunt et subveniunt, scilicet alares; sic isti in omnibus tribulationibus, in ipsa scriptura consolationem, et consolares reperiunt [...]

Quinto sunt charitativi, qui significantur per illos, qui vexilla portabant, quia vexillum et signum militis Christi est charitas [...]

Et sic patent, quales debent esse milites Christi: quia debent esse leves, non gravati pondere terrenorum, custodes et stabiles, non vagantes vanitatibus mundanorum, liberi et non subiecti vilitatibus peccatorum, providi in meditatione sacrarum scripturarum, consignati signo charitatis (ibidem).

Hi ha un petit però interessant detall relatiu a la transmissió material del sermó «Fortis armatus» que crec oportú d'assenyalar en aquest punt, atés que pot servir com a enllaç lògic amb la qüestió que abordaré en les pàgines següents. ${ }^{18} \mathrm{Com}$ és sabut, la versió catalana més elaborada que ens ha pervingut d'aquest text és la de la Quaresma valenciana del 1413, conservada al ms. 273 de l'Arxiu de la Catedral de València. Doncs bé: al marge esquerre del f. CXVIr, que és on es comença a copiar aquest sermó, tot just a l'alçada del passatge on es llegeix «Vejam com se fa [...]» (en què, com hem vist, sant Vicent distingeix entre entre set diferents tipus de tropes dins l'exèrcit de Jesucrist), aquest testimoni presenta l'anotació següent, que sembla deguda a la mateixa mà del copista: «Ab set grans capitans de dimonis havem a batallar: vide in quodam alio sermo$n e »$. Crec que l'apunt demostra que l'anotador estava prou familiaritzat amb el corpus sermonari vicentí com per saber que, per la seua temàtica i la seua estructura, aquesta prèdica està estretament connectada amb una altra que, de fet, podríem considerar el seu revers. Es tracta del sermó per al dimecres després del primer diumenge de Quaresma, que sant Vicent dedica, tot just, a «preÿcar les batalles que-l dimoni nos done» (Ferrer 1975-1988: V, 145). El tema escollit pel dominicà procedeix en aquest cas de la paràbola que Jesús explica a Mt, 12,45 («Assumit septem alios spiritus secum nequiores se»), passatge que, des de ben antic, l'exegesi bíblica va relacionar amb els set pecats mortals, mitjançant els quals el dimoni, l'esperit maligne, tracta d'entrar a les ànimes del homes i dur-les a la perdició. És d'aquests set pecats que ens parlarà sant Vicent, personificats en les figures de set dimonis que, com veurem, esmenta pels seus noms (vet ací un detall important) i presenta com a set poderosos generals de l'exèrcit de Llucifer, diable suprem. Són aquests, per tant, els «grans capitans de dimonis» al-ludits per l'autor de l'anotació del manuscrit dels Sermons de Quaresma.

La meua impressió és que, en l'elaboració d'aquest sermó, el valencià va desenvolupar - incorporant-hi, això sí, molts detalls de la seua collita- un esquema interpretatiu i estructural que es pot trobar en manuals per a predicadors i tractats teològics medievals. En aquest sentit, abans d'abordar-lo convé

18 Vull expressar públicament la meua gratitud envers el Dr. Josep Enric Rubio, de la Universitat de València, que va tenir l'amabilitat de comunicar-me aquest detall. 
considerar breument tres exemples extrets d'aquesta mena de textos, que glossen el mateix versicle de l'evangeli de sant Mateu que, com ha estat dit, constitueix el tema del sermó de sant Vicent. El primer d'ells és un fragment de la Summa o Destructorium vitiorum (pars I, cap. 7) d'Alexander Carpentarius, autor anglés del segle XV, on apareix la imatge dels vicis com a generals de la host del diable:

Praedicta enim peccata septem sunt quasi duces principales exercitus dyabo$l i$, quos ipse ducit secum ad invadendum genus humanum. Unde Luc. XI legitur quod dyabolus volens hominem invadere, assumit septem alios spiritus secum nequiores se, super quo dicit Odo, quod isti septem spiritus sunt septem peccata capitalia que dicuntur peiora dyabolo [...] Primus enim istorum septem spirituum est spiritus gulae [...] Secundus spiritus est spiritus luxuriae [...] Tertius spiritus est spiritus avaritiae [...] Quartus spiritus est spiritus accidiae [...] Quintus spiritus est spiritus superbiae [...] Sextus spiritus est spiritus invidie [...] Septimus spiritus est spiritus irae (Carpentarius 1582: 7a).

El segon és un passatge de la Summa de exemplis et similitudinibus rerum (11. IX, cap. 74) del dominic del segle XIII Giovanni da San Gimignano. Es tracta d'una enciclopèdia moral concebuda, segons declaració expressa del seu autor, com una pedrera de materials per a l'elaboració de sermons, i destinada, per tant, fonamentalment a predicadors. San Gimignano compara el diable amb un rei que ha perdut un dels seus castells i prepara un exèrcit per tal de recuperar-lo. Òbviament, en aquest cas, el castell perdut és l'ànima de l'home, i l'exèrcit del diable és comandat pels vicis, entre els quals la supèrbia fa de portaestendard general (no oblidem aquesta imatge de la bandera, perquè la trobarem, multiplicada per set, en el sermó de sant Vicent):

Item miles vel Rex aliquis, quando castrum amisit, nititur amicos requirere, et congregat exercitum magnum, sicut fecit Pharao ad persequendum filios Israel fugientes ab eo. Sic facit diabolus contra poenitentes [...] Ideo dicitur Luc. quod dum immundus spiritus exierit ab homine converso, tunc dicit: «Revertat in domum meam, unde exivi», et vadit, et assumit septem spiritus nequiores se, etc. Isti septem spiritus, sunt septem vitia, quibus diabolus obsidet animam, quasi rex cum exercitu suo. In quo exercitu superbia quasi vexillum portat (San Gimignano 1597: 486c-d).

El tercer i darrer exemple prové de la Summa theologica (pars III, titulus XVIII, cap. 5) de sant Antoní de Florència, dominic que va començar la seua activitat intel-lectual i predicadora dins aquest orde durant els darrers anys de la vida de mestre Vicent. El seu interés rau ja no tant en el fet que sant Antoní hi parle també de set dimonis responsables dels set pecats capitals i en diga els noms (per altra banda, de seguida veurem que l'onomàstica diabòlica de l'italià no coincideix plenament amb la de mestre Vicent), sinó pel context en què es troba i el seu caràcter metadiscursiu. El passatge fa part d'una secció de la Summa dedicada a la predicació, en què s'apleguen consells i recursos per a la confecció de sermons. Entre aquests recursos, sant Antoní explica una tècnica emprable quan al versicle bíblic escollit com a tema del sermó apareix algun 
numeral, i que consisteix a estructurar-lo i dividir-lo d'acord amb aquest mateix numeral (ens diu, en efecte, que «de vegades el nombre de distincions en què se subdivideix el sermó es correspon amb alguna xifra que apareix al tema esco1lit»). Tot seguit, ens explica de manera pràctica, amb alguns exemples, com es pot aplicar aquesta tècnica, i entre ells posa el cas del número set, bo i al·ludint, tot just, a la citació de sant Lluc que ja coneixem: "Així, en el cas del set: a l'evangeli de sant Lluc es diu que l'esperit maligne va anar a buscar set esperits pitjors que ell». I de seguida aclareix que, en un cas així, és ben natural que el predicador dedique el sermó a glossar qui són aquests set esperits, i que, consegüentment, dividisca la seua prèdica en set parts, cadascuna de les quals dedicada a parlar-nos d'un dels set esperits esmentats al versicle en qüiestió. Si, a més, tenim en compte que en l'exemple posat per sant Antoní aquests set esperits són identificats amb set dimonis, cadascun d'ells al càrrec d'un pecat mortal diferent, trobarem que la tècnica i la interpretació recomanades per l'italià són les mateixes, si fa no fa, que les que sant Vicent posa en solfa en el seu sermó, com de seguida veurem:

\begin{abstract}
Aliquando multiplicantur membra distinctionis secundum numerum, qui ponitur in themate [...] Sicut sunt septem vitia capitalia, ita et septem reperiuntur nomina daemonum, qui de eis tentant [...] Sic etiam reperiuntur septem daemoniaci in sacra scriptura his septem vitiis figurati. Et primus daemon vocatur Mammona [...] et signat avaritiam [...] Secundus vocatur Asmodaeus [...] significat luxuriam [...] Tertius vocatur Sathan [...] signat invidiam [...] Quartus Beelzebub [...] signans acidiam [...] Quintus dicitur Abaddon [...] et tentat de ira [...] Sextus dicitur Behemoth [...] et tentat de gula [...] Septimus dicitur Lucifer [...] et tentat de vana gloria (Florència 1740: III, 1026-1027).
\end{abstract}

Un dels trets del sermó vicentí sobre les batalles dels diables que més poderosament criden l'atenció és el seu desenvolupament marcadament narratiu. De fet, tot ell es pot llegir com un relat centrat a explicar la influència del dimoni en el món i els cors dels humans, un relat que es remunta a la creació de l'home i de la dona i la seua caiguda en desgràcia a causa del pecat original. Al començament de la peça, sant Vicent ens proposa una similitudo castrense per tal d'explicar els orígens del poder del diable a la terra: ens parla d'un escamot de guerrers que, havent-se proposat de capturar alguna de les viles que hi ha a la contrada on es troben, resolen d'atacar en primer lloc una que compta amb una torre fortificada, conscients que si cau en les seues mans la podran fer servir com una base des de la qual sotmetre les altres viles, molt menys poderoses. Això és el que el dimoni (que seria l'escamot de guerrers de la similitudo) va decidir de fer poc després de la creació del món: per tal d'ensenyorir-se de la humanitat (que seria la vila), va capturar Adam i Eva (les dues torres més fortes que aquesta tenia), i aquest fet va condemnar tot el llinatge dels homes. El dimoni és, doncs, un usurpador, un tirà, però aquesta primera etapa de la seua tirania va acabar quan el Fill de Déu el va enganyar i derrotar a la creu. En aquest punt el dominic valencià es fa ressò d'una anècdota procedent de la Historia Scholastica de Pere Comèstor (Historia Evangelica, cap. CLXXII; PL 198, col. 1630), segons la qual el diable va acudir al Calvari i va posar-se sobre el braç esquerre de la creu mentre Jesús expirava, perquè, ignorant que el mori- 
bund es tractava en realitat del Messies, esperava fer-se amb la seua ànima $\mathrm{i}$ endur-se-la cap a l'infern. Però les coses, com ens explica el valencià, anaren de tota una altra manera, perquè en aquell mateix instant l'ànima de Jesús descendí als inferns, n'abaté les portes i en tragué les ànimes dels bons i justos, que hi havien romàs captives des de l'època del pecat original. Per la seua banda, Llucifer, enganyat i vençut, restà empresonat al seu regne subterrani:

Ara, sapiau que doctrina és comuna que $\cdot$ l dimoni, e.l principi del món fins a Jesuchrist, havie senyoria sobre aquest món. Sabeu com? Veus que seran alguns hòmens d'armes e diran: "Anem a guerrejar tal vila, e si la podem prendre, serà nostra». E veus que $n$ van e combaten-la e prenen una torre, la pus fort de totes les altres, e ab aquella prenen les altres. Axí féu lo dimoni, que anà a combatre les pus forts torres del món, ço és, Adam e Eva, e aprés fahye's adorar a les gens del món. Veus ací la senyoria que havie; mas emperò no la havie per dret, mas per tirannia, e prengué aquella senyoria en tant que ere appellat príncep de aquest món, e Déus també [...] Mas quan Jesucrist vingué, ell lo lançà de fora, e açò en la creu, quan estave crucificat [...] E per ço, quan Jesucrist stave crucificat, lo dimoni vingué e posà's en la creu, en lo braç sinistre, sperant quan exirie la sua ànima del cors, que la prengués. Mas quan l'ànima de Jesucrist isqué del cors, ell conegué llavors que ere Déu e volch fugir, e Jesucrist dix: "No, en traÿdor, que yo us tinch ara, e lligat en infern!» E veus ací com prengué la senyoria Jesuchrist, e com perdé lo dimoni la sua senyoria que havie per tirannia (Ferrer 1975-1988: V, 145-146).

D'ençà d'aquesta derrota, el dimoni roman confinat a l'infern i no pot fer-se present de manera directa al món. Però, si això és així, ¿com és que els homes segueixen sucumbint a la temptació i cometent pecats mortals? A respondre aquesta pregunta dedica sant Vicent la resta del sermó, i ho fa acudint al passatge de sant Lluc que n'és el tema: després de ser empresonat a l'infern, l'esperit maligne va anar a buscar set esperits pitjors que ell. Qui són aquests esperits? Així els presenta sant Vicent:

E donchs, veus ací com Jesuchrist lligà a Lucifer en infern. E donchs, ¿com nos tempte ara, si lligat és? O, com lo tema respon: «Assumpsit», etc. E sapiau que són set dimonis que han sos noms propris, e són capitans de molts altres dimonis, per aventura que cadahú de aquells ha mil mília dimonis sots si. E quan Lucifer nos vol temptar, ell veu que ell no y pot venir, veus que appelle aquests VII capitans que vinguen a nosaltres e que guerrègon contra nosaltres (Ferrer 1975-1988: V, 146).

El primer capità a ser invocat per Llucifer es diu Leviatà, el dimoni que fa caure els homes en el pecat de la supèrbia. El predicador reprodueix en estil directe les ordres que el Maligne dóna al seu general:

Ad practicam: Primo appelle hun dimoni que ha nom Leviatan [...] E diu-li: «O, Leviatan, vet com estich pres ací e com Jesuchrist me apresona, per què yo no puch anar en lo món; mas si tu me volies ajudar, que anasses al món, e que batallasses per mi, e, pus que no podem noure a Jesucrist ne als seus sants 
qui són en paraís, almenys que guerregasses la sua gent que són en lo món, qui creen en ell e a sos servidors. E axí vés-hi» (Ferrer 1975-1988: V, 146147).

Tot d'una el Leviatà es posa en marxa al capdavant del seu escamot de dimonis, brandant desplegat — tal com hem vist en el Liber de Giovanni da San Gimignano - un estendard en què figura escrit un lema compost per una parella de sinònims: «E aquell ne va per lo món ab bandera estesa. Plàcie-us-o veure. Lo títol és supèrbia e vanitat» (Ferrer 1975-1988: V, 147; no sembla, per cert, agosarat de postular que el «Plàcie-us-o veure» de sant Vicent devia acompanyar-se d'una indicació gestual cap a alguna mena de representació visual del dimoni en qüestió). Tot seguit se'ns expliquen els devastadors efectes que la intervenció del dimoni de la supèrbia provoca en el món: a causa de la seua efectiva temptació, els reis i emperadors, cobejosos de riqueses, es dediquen «a robar la pobra gent», i els jerarques de l'Església duen una vida plena de luxes en comptes de predicar la paraula de Déu:

E féu tant de mal e ha-u continuat, que tot és ja supèrbia. E com? Veus que ell vingué e entrà en les cases dels grans senyors, axí com emperadors, reys, etc., e féu tant que tot és supèrbia e vanitats, que ja no y basten les rendes, per què han a robar la pobra gent ab demandes gracioses et aliter. Oo, traÿdors! Ítem, vingué e entrà en les cases dels prelats, papa, cardenals, bisbes, arquebisbes, abats, rectors, vicaris e officials, e tot ó omplí de vanitats, que tant són los encortinaments e los cavalls e mules e vexella d'argent e de or, e vestís e forradures, que la renda no y baste, per què han a fer symonia. Oo, traÿdor! (ibidem).

Quant a la manera com Vicent imagina la mobilització del Leviatà i les seues tropes, cal tenir en compte que l'ús d'ensenyes amb lemes i inscripcions era una pràctica habitual en els exèrcits medievals. Hom pot pensar, per exemple, en l'estendard del cigne amb el lema «Dieu et mon droyt» que, segons vol la tradició, va ser emprat pel rei Enric V d'Anglaterra a la batalla d'Agincourt (1419); o en el cèlebre estendard del porc senglar del rei Ricard III, amb el lema «Loyauté me lie». En el camp de les nostres lletres medievals, cal recordar que Joanot Martorell — home que, com és sabut, sentia una profunda estimació per tot allò que tenia a veure amb l'ornamentació i la parafernàlia cavalleresquesens va deixar al seu Tirant lo Blanc descripcions molt detallades d'aquesta mena d'estendards: basta citar, per exemple, el cap. 107 del llibre, on se'ns parla de l'expedició contra Constantinoble del Gran Turc, al capdavant d'un nombrós exèrcit que seguia una «bandera de terçanell verd ab lletres d'or qui deien: "Venjadors d'aquella sang d'aquell benaventurat cavaller don Hèctor lo troià"» (Martorell 2004: 415); o el cap. 132, en què es descriu la bandera de la divisa de l'emperador grec, «la qual era ab lo camper blau ab la torre de Babilònia tota d'argent, ficada una espasa dins la dita torre $a b$ un braç tot armat qui tenia l'espasa per lo mantí ab un mot de lletres d'or qui deien: “Mia és la ventura"» (Martorell 2004: 543). 
Sens dubte, l'al-lusió a la bandera i al lema que conté és una prova del grau de detall i sofistificació de l'al-legoria militar desenvolupada per sant Vicent. Ara bé, no hauríem de pensar que la inclusió d'una imatge com aquesta al sermó té una finalitat merament estètica: ben al contrari, es tracta d'un mecanisme que el predicador aprofita per a cohesionar tot el text, a còpia d'una evident reiteració estructural. Així ho sembla suggerir el fet que, en les sis parts subsegüents de la prèdica, dedicada cada una d'elles a un capità infernal diferent, aquest personatge aparega invariablement al capdavant d'un esquadró de dimonis i brandant, també, a la mà un estendard amb un lema personalitzat, on s'explicita, per mitjà d'una parella sinonímica, el pecat que li és associat. Cal subratllar, a més, que els lemes de les banderes esmentades a les diferents subdivisions del sermó rimen entre ells:

\begin{tabular}{|l|l|}
\hline \multicolumn{1}{|c|}{ Capitans de Llucifer } & \multicolumn{1}{c|}{ Títol de la bandera } \\
\hline Leviatà & Supèrbia e vanitat \\
\hline Mammona & Avarícia e cupiditat \\
\hline Asmodeus & Luxúria e carnalitat \\
\hline Belzebuc & Enveja e irascitat \\
\hline Belfagor & Gola e voracitat \\
\hline Benialberit & Ira e iniquitat \\
\hline Baalim & Perea e ociositat \\
\hline
\end{tabular}

No és, però, la bandera l'únic element que es repeteix en les diferents parts del sermó, que, de fet, presenten totes una estructura calcada de la que tot just ha estat analitzada. És a dir: en primer lloc, sant Vicent ens dóna el nom del dimoni de torn i ens diu amb quin pecat tempta els homes; seguidament ens explica com el diable suprem, Llucifer, convoca davant la seua presència el seu vassall i li ordena - amb unes paraules que són sistemàticament reproduïdes en estil directe pel sermonador- d'anar pel món guerrejant i conquerint les ànimes dels creients; llavors el general invocat mobilitza els seus dimonis i recorre el món amb el seu estendard desplegat, duent a terme la ràtzia que el seu senyor li ha ordenat; finalment, sant Vicent ens explica les conseqüències que aquest atac demoníac té sobre la humanitat, sempre desastroses. Quant a aquest darrer punt, ja hem vist que en parlar del Leviatà, capità de la supèrbia, el valencià carrega contra l'orgull i l'ambició d'autoritats civils i eclesiàstiques; per la seua banda, Mammona, capità de l'avarícia, ha provocat que quasi tot el món haja caigut en la vil pràctica de la usura, abans exclusiva dels jueus; Asmodeus, capità de la luxúria, «féu tant de mal, que tot és ja corrumput, que quasi matrimoni no s'hi salva» (Ferrer 1975-1988: V, 148); Belzebuc, capità de l'enveja, fa que tothom malparle del seu proïsme; Belfagor, capità de la gola, que els cristians ja no dejunen i es donen a «menjar e beure» (ibidem) fins i tot en les festes sagrades; Benialberit, capità de la ira, mou guerres i divisions entre els senyors del món, i la discòrdia entre marit i muller; i, en darrer lloc, Baalim, capità de la peresa, fa que els preveres no tinguen esma per llevar-se a dir matines, sinó que diguen afirma sant Vicent, amb evident causticitat — «matines blanques, al sol eixit, o 
roges de vespre» (Ferrer 1975-1988: V, 149), i que els pocs que les diuen a l'hora escaient ho facen mig endormiscats i desganadament.

\section{IV.- SETGE ESPIRITUAL: EL CASTELL AL·LEGÒRIC}

En altres ocasions, el conflicte entre el bé i el mal és expressat per sant Vicent ja no com un duel, ni com un combat a camp obert, sinó com un setge o un assalt contra una fortalesa. Tal com explica Contamine (1980: 219), el setge era la pràctica guerrera més habitual dels segles medievals: en efecte, tot i que hom sol recordar sobretot les batalles campals, el ben cert és que aquestes es produïen molt excepcionalment, mentre que els setges eren més freqüents. Aquesta operació militar podia tenir diferents desenllaços: el castell assetjat podia resistir els embats de l'enemic i forçar aquest a dessistir del seu propòsit i emprendre la retirada; o bé, el lloc podia caure en mans enemigues després d'una resistència heroica de la guarnició, finida amb un virulent atac final en què el lloc era reduït a foc $\mathrm{i}$ sang pels assaltants, que llavors es feien amb un botí immens; o bé, a causa de la fam i d'altres penalitats, els pobladors del castell podien pactar amb l'enemic la rendició i lliurar-li la plaça; o, encara, entre els membres de la guarnició podia haver-hi també algun traïdor que, convenientment subornat, obrís discretament a l'enemic alguna de les portes de la murada. Enumere aquests escenaris perquè tots ells apareixen, emprats amb diferents sentits al·legòrics, en les imatges sobre castells que es poden llegir als sermons vicentins.

D’entrada, cal dir que la del castell és una de les al·legories més conegudes de la cultura europea medieval: apareix de manera molt freqüent, per exemple, en la literatura de tema amorós. En aquest context, el setge o l'atac a la fortalesa simbolitza el procés de seducció de la persona amada per part del seu pretenent: l'enamorat seria, doncs, l'exèrcit assetjador; l'amat o l'amada, la fortalesa que cal conquerir; i el setge, de durada variable, segons els casos, tots els intents de l'enamorat per conquerir - verb que ací cal entendre com un eufemisme sexual evident - el seu objectiu. Basta citar el cas del Roman de la Rose, escrit per Guillaume de Lorris i Jean de Meun al segle XIII, un immens poema al·legòric en què el setge representa els esforços del protagonista — finalment reeixits, mercès a l'ajuda del Déu d'Amor- per guanyar-se el cor i el cos de la seua dama.

Però si en el cas del Roman el Déu d'Amor combat a favor de l'enamorat, en d'altres ocasions també pot ser presentat com un antagonista. En les nostres lletres medievals, per exemple, hi ha el famós poema Lo setge d'Amor de Jordi de sant Jordi, en què el jo líric es presenta com un castell a punt de ser conquerit per l'exèrcit de l'Amor, que treballa per a fer-lo caure en mans de la dama («Ajustat vey d'Amor tot lo poder, / e sobre me ja posat son fort siti», vv. 1-2; Sant Jordi 1984: 105); i en la lírica castellana del segle XV trobem la mateixa casuística, per exemple, en els sonets del marqués de Santillana («Sitio de amor con grande artillería / me veo en torno, e con poder inmenso», vv. 1-2; López de Mendoza 1997: 208) i l'Escala de amor de Jorge Manrique, on és la 
bellesa i les altres qualitats de la dama les que escalen els murs del castell de l'enamorat, ajudades pels ulls d'aquest, presentats com uns guardians traïdors que han deixat via lliure a l'enemic («Estando triste, seguro, / mi voluntad reposava / cuando escalaron el muro / do mi libertad estava; / a escala vista subieron / vuestra beldad y mesura / y tan de rezio hirieron / que vencieron mi cordura», vv. 1-8; Manrique 2013: 22). Encara, a aquesta tria d'al-legories castrenses en clau amorosa hauríem d'afegir el cas del cap. 436 del Tirant lo Blanc, que porta el significatiu títol «Com Tirant vencé la batalla e per força d'armes entrà lo castell», i que, com és ben conegut, no narra cap batalla en el sentit literal del terme: es tracta del capítol en què Tirant aconsegueix de satisfer la seua passió amb Carmesina, que respon als seus avanços amb un prec molt freudià expressat també en clau militar: «Que no deuen tallar les armes d'amor, no han de rompre, no deu nafrar l'enamorada llança!» (Martorell 2004: 1418). ${ }^{19}$

També els teòlegs i predicadors medievals van recórrer en les seues obres a al-legories i semblances relacionades amb setges i castells, atorgant-los, per descomptat, un significat diferent al que suara hem explicat: un significat espiritual, relacionat amb Déu, el cel o la puresa o la corrupció de l'ànima humana; de fet, interpretat en clau divina o transcendent, el castell era un símbol polisèmic, el sentit del qual podia variar segons el cas i la conveniència. ${ }^{20}$ Els textos que jugaven amb imatges d'aquest estil, com ara els sermons de sant Vicent, solien desenvolupar-les a partir de la lectura, convenientment descontextualitzada i passada pel sedàs dels diferents nivells d'interpretació escripturística propis de la teologia medieval, d'alguns versicles bíblics en què, efectivament, apareixia el mot castellum (mot que, com és sabut, en llatí medieval no sols tenia l'accepció de fortificació militar, sinó també la de vila o població situada en una posició poc o molt elevada). Un exemple famós d'aquesta mena de lectura el tenim en el passatge de Lc 10,38 («Intravit Iesus in quoddam castellum»). En quin context narratiu se situa aquesta frase? El text bíblic reconta l'arribada de Jesús a la vila de Betània (vet ací el castellum en qüestió), on és acollit a la casa de Marta, Maria i Llàtzer. Treta de context, però, o — per expressar-ho d'una manera més apropiada - reinterpretant-ne el context en clau al·legòrica, l'al·lusió a l'entrada de Jesús en aquest edifici esdevenia un símbol de la seua encarnació: el castellum o castrum seria el ventre de la verge Maria, un castell inexpugnat que a causa de la seua puresa fou jutjat digne d'acollir entre els seus murs el Fill de Déu. Aquest és, per exemple, un dels sentits amb què la paraula castell apareix associada a la ja esmentada Summa Praedicantium de John Bromyard (s.v. anima), que ofereix als seus lectors predicadors tres possibles maneres de glossar al-legòricament el concepte en els seus sermons: la primera, ja ho hem vist, és identificar-lo amb la Verge, una identificació establerta a partir, tot just, del passatge de sant Lluc que ja hem discutit; la segona, establir un paral-lelisme entre el castell i les ànimes dels bons, aquells

19 Vegeu el treball de Hauf (1997), dedicat tot just als eufemismes amorosos de tipus bèl-lic en la novel.la martorellana.

${ }^{20}$ La crítica ha dedicat força atenció als diversos desenvolupaments de l'al-legoria del castell en la literatura, la teologia i la cultura medievals: a banda del treball clàssic de Cornelius (1930), vegeu els estudis molt més recents d'Hebron (1997) i Wheatley (2004: 78-111). 
que espiritualment tenen la força suficient per a resistir l'assalt de les temptacions del diable, talment com un castell molt fort és capaç de resistir el setge dels seus enemics (observem, a més, que en aquest cas Bromyard desenvolupa l'allegoria i ens diu quines són les parts o defenses d'aquest castell de l'ànima justa: els seus fonaments són la fe; el mur, la caritat; el donjon o torre de l'homenatge, l'esperança; els quatre bastions o baluards que protegeixen la murada, les quatre virtuts cardinals; les cinc portes que hi donen accés, els cinc sentits corporals; el porter que les vigila, la voluntat, que si és lleial, haurà d'obeir el castellà o capità del castell, que és la raó); finalment, la tercera manera d'entendre el castellum ens presenta un paral-lelisme de signe invers al que acabem de veure: en aquest cas, el castell és l'ànima dels pecadors, aquells esperits febles que han sucumbit al setge dels vicis capitals, custodis de la fortalesa en nom del seu senyor, el diable:

Est quarto anima sancta castrum Dei. De triplici enim castro legimus, duo sunt Dei, et tertium est diaboli. Primum est beata virgo Maria, in quod Iesus intravit, Luc. 10: Intravit Iesus in quoddam castellum. Secundum sunt animae sanctae [...] Tertium sunt animae impiorum [...] Secundo vero castri fundamentum est fides. Aliud enim nemo potest ponere, murus charitas, cingens et circuiens, scilicet amicos et inimicos. Alta turris spes, menia alie virtutes, porte quinque sensus ${ }^{21}[\ldots]$ Posticum occultum cordis cogitatio, ianitor voluntas, castellarius seu constabiliarius ratio [...] Tertium castrum, videlicet quod aedificatur diabolo in animabus impiorum, dicitur validum in mundo isto, quia habet multos castellanos, et plurimos ei intendentes. In isto castro est turris vanitatis et superbiae, et ad istam turrim sunt multi attendentes [...] Secundo in isto castro locum iusticiarii tenet ira [...] Tertio in isto castro peccatum cupiditatis est thesaurarius [...] Quarto in isto castro locum coquinarii tenet gula [...] Quinto in isto castro magnum hospitium tenet luxuria [...] Sed in isto castro camerarius et peccatum accidie [...] Sic ergo patet quando in animabus impiorum est castrum inimici contra castrum Dei (Bromyard 1586: I, 62b-c).

Tots aquests significats al-legòrics del castell es retroben en la predicació ferreriana. Considerem, per exemple, un fragment d'un sermó dedicat a l'Assumpció de santa Maria, en què sant Vicent glossa, precisament, el ja consabut versicle «Intravit Iesus in quoddam castellum». Com és esperable, l'entrada al castellum és identificada amb la concepció de Jesús al ventre de la Verge, però, al mateix temps, el dominic atorga un segon sentit al passatge: el castellum, en efecte, seria també aquest món, una fortalesa que havia caigut en mans de Llucifer, i que Jesucrist volgué assetjar i reconquerir mitjançant la seua encarnació i el seu sacrifici pels homes a la creu. Com en el text de

21 La idea que els cinc sentits són els porters del castell de l'ànima apareix en altres manuals de predicació, com ara el Fasciculus Morum, compost per un frare franciscà anglés de nom inconegut a començaments del segle XIV: «Quarto necessarium est illud [castrum] firmum et clausum tenere, quod facit quando sensus hominis restringuntur ab illicitis; sensus enim sunt quasi porte cordis, per quos hostes ingredi possunt. Qui autem pacem perturbant maxime in illo sunt carnales concupiscencie» (Wenzel (ed.) 1989: 144). 
Bromyard, ací sant Vicent també desglossa les parts d'aquest castell controlat pel diable, que són igualment identificades amb els set pecats mortals: la seua elevada altària i els seus murs poderosos representaven la supèrbia; les seues torres, l'avarícia; el profund vall o fossat que el circumdava, la luxúria i l'enveja; les abundants provisions que contenia, la gola; les armadures amb què es cobria la seua guarnició, la ira i la peresa. Per tal de dur a terme la seua conquesta, segueix explicant el sermó, Jesucrist convocà els seus capitans, els apòstols, i els ordenà de marxar contra el castell i capturar-lo, ço és, de predicar l'evangeli pel món i convertir els pobles, si traduïm l'al-legoria implícita en el fragment, que remet en aquest punt a Mt 21,2 («Ite in castellum quod contra vos est»). Vet ací un altre exemple ben clar de citació descontextualitzada: si bé és cert que, considerada aïlladament, la frase de Jesús reproduïda pel predicador sembla l'ordre que un general donaria als seus guerrers perquè vagen a atacar un lloc determinat, en realitat el context del passatge té més aviat poc d'èpic: en ell, senzillament ens trobem un Jesucrist que ordena a dos dels seus deixebles que entren a la vila de Betfagé i li porten una somera i un pollí que hi ha a l'entrada d'aquesta població. El passatge, però, solia ser interpretat per la teologia i la predicació medieval en el mateix sentit que hem vist en sant Vicent:

Diu que Jesuchrist, quan anave preÿcan per lo món, diu que hun dia entrà en hun castell, e negun hom ne dona no.l rebé sinó santa Marta, germana de santa Maria Magdalena. Ideo dicit: «Jesus intravit».

Ara, açò pensat que face per la verge Maria. Secret hi ha. Veus ací la primera part: com Jesuchrist entrà en la verge Maria, ço és lo castell, en la sua concepció. Dirie algú: «Aquest món és dit castell?» Dic que hoc: lo qual ere alt per supèrbia, lo qual tenie Lucifer, e ere murat per supèrbia contra Déu, ere entorrat per avarícia, ere vallegat per luxúria e enveja, ere provehit de vitualles per gola, ere armat de armadures malicioses per peccat de ira e de accídia, que tots dormien en peccat. Aquest castell ere armat contra Déu. Vench Jesuchrist a conquestar-lo, e contra aquest castell tramès los seus apòstols, dient-los: «Ite in castellum, quod contra vos est» $\left(\right.$ Mat., $\left.21^{\circ} \mathrm{ca}^{\circ}\right)$. En aquest castell entrà Jesuchrist lo dia de la sua beneita incarnació. (Ferrer 1975-1988: III, 74-75).

En altres sermons, el castell simbolitza l'ànima humana, que tracta de resistir l'escomesa del dimoni. Així, en un sermó per al divendres posterior al vuité diumenge després de la Trinitat, sant Vicent encoratja el seu auditori a resistir contra aquest oponent tan implacable: igual com una guarnició que ha de defensar un castell vigila bé que l'enemic no hi entre per cap dels seus portells, així mateix el cristià ha de vigilar bé perquè el dimoni no li prenga el castell de l'ànima entrant per algun dels cinc portells que té, que són els cinc sentits corporals, els quals, si es lliuren a plaers immoderats o obren de manera deshonesta, deixen la porta al pecat i poden causar, doncs, la caiguda del castell en mans enemigues, ço és, la perdició de l'ànima (convé notar que la identificació entre les portes del castell i els cinc sentits és també la mateixa que hem vist en la Summa de Bromyard o en el Fasciculus morum): 
Axí matex, nosaltres havem gran perill, e los pus forts enemichs, e és pigor, que no.ls podem veure, si bé.s van entorn de nosaltres per fer-nos peccar, e són molts; e donchs, ¿no devem vel·lar que no siam escalats? E axí guardem la vista, que no·y pecquem; si no, lo castell se escalarà per aquest portell dels huylls. Lo cors e l'ànima és castell [...] Axí matex, guardat lo portell de les orelles, que.l castell no sia pres per aquell: fuyg a difamacions. Axí matex guayta lo odorar, no fer superfluïtat per dar plaer al cors. Axí matex, per la boqua parlant indiscretament, mengar e beure tempradament. Aquests són los portells perillosos, los quals devem regir molt bé (Ferrer 1975-1988: III, 92).

El dominic ens alerta contra les males arts del diable, que presenta com un general astut que s'agrada de recórrer a paranys i estratagemes per a derrotar i capturar les seues víctimes. Ho fa, molt significativament, referint una història inspirada en els ja esmentats Strategemata de Frontí (11. I, cap. 5, § 28):

Axí matex guardat tot l'altre cors; e no vos prengue axí com a hun castell qui ere molt fort a la una part, e a l'altra no molt, e ere assetjat per enemichs, e aquests, vehent que bonament no·y porien entrar, diu que de nit prengueren dues o tres barques que havie aquí en una aygua davant la part menys fort del castell, e meteren-hi cabres e posaren-los candeles cremants a les banes per a fer-los badar a los del castell per la part menys fort, per tal que poguessen escalar la part pus fort; e los del castell véren axí les cabres, digueren: «Allò ànimes són», e axí se aboquaren tots per mirar a la part menys fort, e los enemichs escalaren tost lo castell e prengueren-lo (ibidem).

Tot seguit se'ns explica el significat d'aquesta història. A molts pecadors els esdevé el mateix que als guerrers que es concentren molt a defensar una part del castell i deixen l'altra desemparada: és a dir, es guarden molt bé de caure en un pecat determinat, però mentrestant el diable aconsegueix de fer-los caure en un altre de molt pitjor; en aquests casos, pot passar que el pecador es pense que està fent allò correcte, quan en realitat en eixe mateix instant el diable està escalant secretament, d'una manera que ell ni tan sols pot arribar a sospitar, els murs del castell de la seua ànima. Per tal d'il-lustrar aquest punt, sant Vicent explica un curiós exemplum que té com a protagonista una monja que, en ser forçada per un home, no va voler cridar ni demanar auxili per no trencar el vot de silenci que havia fet:

Ara, bona gent, en aquesta forma són escalats molts hòmens. Verbi gracia, molts són qui volen guardar la ànima, que és castell, e tenen esment que no volen pecquar en supèrbia, ans se donen a humilitat, que no volen contrastar a res. E diu lo dyable: «Yo us pendré». Ve lo dyable: «E yo vos faré caure». Axí com de la monga forçada que no volgué trenquar lo vot de silenci, avet com caygué e fo pres lo castell, ço és, la ànima. E pres-li axí: que féu vot de tenir silenci, e esdevench-se que hun hom la forçave, e per no trenquar lo vot de silenci, no dix res, no parlà, sinó que deye hun «hu-hu». E fo sabut per la aba- 
dessa, e reptà-la perquè no havia dit queacom; e aquesta dix que no gosà per servar silenci. Aveus com pecquà (Ferrer 1975-1988: III, 93). ${ }^{22}$

Hi ha, encara, un tercer ús de la imatge del castell detectable en alguns sermons vicentins, que es basa a establir una equiparació entre el setge d'una fortalesa per part d'un exèrcit i l'assoliment de la salvació eterna per part de l'ànima: és a dir, de la mateixa manera que, en un setge, els atacants fan servir tot tipus d'artilleria i màquines de guerra per enderrocar els murs del castell, el creient fa servir també diversos recursos, en forma de penitències i bones obres, per conquistar la vida eterna i el Paradís celestial. Vegem un exemple d'aquest tipus de tractament al-legòric en el passatge següent, extret d'un sermó llatí per al Diumenge de Rams, en què el dominic ens ofereix una elaborada llista d' «armes» que permeten a l'ànima d'apoderar-se del regne de Déu: així, les bombardes són comparades en aquesta peça amb la confessió del pecador, que llança fora els pecats igual que la bombarda llança projectils; els trabuquets i altres ginys similars són l'almoina, que el cristià ha de fer discretament i callada per guanyar-se la glòria del cel; la ballesta, com ja hem vist més amunt, és l'oració; i l'escala per pujar els murs del castell és l'escala de les virtuts, els graons de la qual són la humilitat, la castedat, la pobresa, la temprança i la justícia:

Ideo tanquam boni bellatores debemus obsidere castrum celi et ipsum impugnare. Primo cum bombardis, quod fit per lamentabilem confessionem. Sicut in bombarda est foramen, ubi ponitur pulvis, et magister mittit ferrum ignitum, et pulvis inflammatur, et lapis sic mittitur contra castrum, et capitur, isto modo in confessione foramen, ubi est pulvis niger, et fetidus peccatorum est cor vel memoria, ubi debent congregari peccata. Ferrum ignitum est compunctio seu contritio cordis, que a magistro seu a Spiritu sancto mittitur, et inflammatur cor, et tunc proiicitur lapis magnus peccati mortalis, et perforatur murus Paradisi [...] Secundo trabucando per secretas miserationes. Trabuccus etiam [lapides] mittit contra castrum, sed non cum clamore nec sonitu, sicut bombarda, sed secrete. Sic eciam est de elemosina, que secrete est fienda [...] Tercio, balistando per efficaces orationes, unde os nostrum ad instar baliste est factum duorum lignorum, labium. Arcus baliste est lingua, sagitta vero oratio, et lig-

${ }^{22}$ Com es pot apreciar, aquesta historieta ens ofereix un divertit exemple de la tendència vicentina a introduir en la seua predicació onomatopeies, interjeccions i tota mena de sons enginyosos, acompanyats molt sovint amb una rica varietat de gestos il-lustradors (Martínez 2002: 156-159; Ysern 2015: 78-87). Es tracta d'un fenomen clarament advertit ja, per exemple, en una carta adreçada a l'infant Ferran d'Antequera en què es lloava la capacitat comunicativa del nostre predicador. L'autor de la carta, que havia tingut l'oportunitat de veure i escoltar de viva veu Ferrer durant les seues campanyes de predicació a terres del regne de Castella, parlava en termes encomiàstics de «las autoridades e sutilezas e instruiçiones e dotrinas e moralidades e enxenplos por donde funda lo que dice, e gestos que sobre ello faze, ca non ha en el mundo cosa que diga por la boca de que non faga el gesto como lo dize» (Cátedra 1994: 672). Bé: si això és cert - i no tenim cap motiu per a dubtar de les paraules d'aquest testimoni directe- hom no pot deixar de demanar-se com devia interpretar sant Vicent la interjecció que ara ens ocupa en un context narratiu com el de la història de la monja. Com que es tracta, però, d'una qüestió delicada, m'estime més de remetre la resposta a aquest interrogant a la imaginació del lector. 
num per medium arcus est rectitudo orationis [...] Quarto, scalando castrum per scalam virtutum, ascendendo ad instar hominum armorum, qui cum scala ascendunt secrete, et quando sunt superius clamant fortiter: «Vivat, vivat!». Ita bona vita et virtuosa est scala, cuius gradus est humilitas, castitas, paupertas, temperantia, iusticia etc. (Ferrer 1485: s.f.).

Des de la nostra òptica moderna, hom podria pensar - i tindria, potser, bones raons per a fer-ho- que a l'hora de desenvolupar una al-legoria com la que acabem de llegir el sant va carregar massa la mà. Ara bé, convé no obviar que hi havia predicadors coetanis del valencià que eren capaços d'elaborar la mateixa idea d'una manera encara més artificiosa i sofisticada. Un d'ells era, per exemple, el ja esmentat sant Bernardí de Siena, autor d'un sermó en el qual compara el moment en què les ànimes dels bons entren a la Jerusalem eterna amb el desenllaç exitós de l'assalt a una gran ciutat, quan els murs d'aquesta han caigut $\mathrm{i}$ els assaltants ja campen sense oposició pels seus carrers. En aquest text, entre el catàleg d'armes metafòriques amb què segons Bernardí l'exèrcit dels virtuosos tracta de guanyar-se l'urbs celestial, ens tornem a trobar les bombardes, que ací simbolitzen, però, el fervor i l'amor ardent a Déu; i també les escales, que representen les meditacions dels contemplatius, per mitjà de les quals pugen espiritualment fins al cel; però ací els atacants disparen, a més, manganells, que representen els bons pensaments; o ariets, el valor simbòlic dels quals no s'hi explicita. Per tal d'accedir, però, a l'interior de la ciutat, els guerrers de Crist han de superar encara un obstacle ben difícil: el fossat de les possessions terrenals; només aquells que ho fan poden entrar joiosos al cel i gaudir de les seues riqueses. Notem que els crits amb què aquests soldats celebren la seua victòria són del mateix estil dels que hem llegit abans en el text vicentí:

Interea constituuntur bombardae cordialium ardorum, atque clamorum ex fervore spiritus emissorum, quae violento impulsu concutiunt atque confringunt muros et alta moenia civitatis. Constructa etiam manganorum, id est, mentalium actionum, civitatis muros et moenia feriunt ingentes saxorum moles, et lapides lapidibus illiduntur, ut ex crebra saxorum collisione secreta coeli mysteria revelentur. Aplicantur interea ad murum machinae operum perfectorum, et fortibus pugnatoribus interpositis, aggrediuntur cominus propugnatores urbis. Interea inspirata velocitate subito muris applicantur scalae coelestium speculationum, per quas veloci ascensu milites scandunt, se per visibilia ad invisibilia rapientes. Astant quoque fervoribus importunis, audaci conatu subito scandunt muros, perstrepunt milites clangentium et laudantium buccinarum, clamoresque fervorum vociferantis exercitus, ac dicentis: «Praedor, praedor, praedor!», totam civitatem in admirationem et stuporem adducunt. His denique in hunc modum certantibus, et machinis et propugnaculis aliisque mirabilibus armis et modis fortissime dimicantibus, vulnerant et vulnerantur, inde reportantes vulnera pietatis. Istis igitur violentiis atque violentis ictibus franguntur et aperiuntur coelestis Hierusalem muri; iamque conspiciuntur quae intus sunt vel fiunt. $\mathrm{Nec}$ ista sufficiunt, sed vallo humilitatis, quod civitati circunstat repleto sensu propriae vilitatis, confractisque vallis corporalium rerum, admoventur ad murum multitudines arietum; et, intercu- 
rrente directa ratiocinatione, validis argumentorum ictibus murorum subilimitas tandem hincinde dissolvitur, moeniaque urbis vario machinamentorum impulsu undique lacerantur, et iam illa profunda altitudo divinorum mysteriorum penetratur. Fractoque muro ibi spisso in figuris, et structo aenigmatibus sacris, tunc irruunt undique fortes, alta voce clamantes: «Vivat Iesus, vivat Iesus, vivat Filius Dei Dominus Iesus Christus!». Et perscrutantes scrutinio, irrumpunt audaciores, et plateam civitatis intrantes, penetralia divini palatii ingrediuntur (Siena 1650: I, 354).

\section{V.- CONCLUSIONS}

Per descomptat, la casuística de símils i al·legories bèl-liques als sermons de sant Vicent Ferrer és molt més abundant i complexa del que hem pogut veure ací; fer-ne un inventari exhaustiu, però, ultrapassa els límits del present treball, el propòsit principal del qual ha estat, senzillament, d'oferir una mostra del paper que aquesta mena d'imatgeria té en la predicació del dominic valencià.

Les imatges de caire militar que trobem en el corpus sermonari vicentí conservat en llengua catalana apareixen tot sovint introduïdes en forma d'historietes o escenes puntuals el rerefons teològic i moral de les quals el sant es cuida de deixar ben establert tot seguit, i que s'ajusten, per tant, al format més habitual de la similitudo, tal com aquest procediment retòric és definit a les artes praedicandi medievals. Entre les similitudines que segueixen l'esquema suara descrit, hi trobem un primer grup en què Ferrer recorre al motiu del Christus miles i presenta Jesucrist com un cavaller que lluita per alliberar la humanitat de la màcula del pecat original. El predicador elabora aquest motiu en dues direccions diferents, sobretot: així, en alguns sermons descriu l'episodi bíblic de les tres temptacions al desert com una justa cavalleresca entre Crist $\mathrm{i}$ el diable; en d'altres, se subratlla la condició de Jesús com a intercessor entre Déu i els homes bo i recorrent a la història de Juli Cèsar i les nafres d'Antípater, en una associació que es retroba, per exemples, en textos com ara l'Speculum Humanae Salvationis.

De vegades, el recurs a les similitudines condiciona no sols el contingut, sinó també la forma i el disseny d'alguns dels sermons ferrerians. Aquest és el cas de les diferents redaccions del sermó sobre el tema «Fortis armatus custodit atrium suum», bastit íntegrament com una llarga similitudo en què, tot al-ludint a l'autoritat del De re militari de Vegeci, sant Vicent equipara el conflicte que els cristians mantenen contra els vicis i les temptacions durant la Quaresma amb el capteniment d'una host en formació de combat. Convé fer notar que, temàticament $\mathrm{i}$ estructuralment, aquesta peça sembla estar estretament connectada amb el sermó sobre el tema "Assumpsit septem alios spiritus nequiores se», dedicat als set capitans que lideren la host amb què el diable tempta la humanitat, text que, d'altra banda, palesa en el seu desenvolupament el recurs a una tècnica retòrica que consisteix a estructurar les parts del sermó d'acord amb el numeral que apareix al tema, en aquest cas el número set. 
Cal assenyalar, en darrer lloc, la notable recurrència de símils i al-legories relacionades amb castells i setges dins l'obra de sant Vicent. En els seus sermons el castell espiritual se'ns apareix com un símbol d'una natura altament polisèmica —una natura subratllada també, per cert, en tractats de predicació com ara la Summa Praedicantium de John Bromyard-, que és emprat flexiblement en un o un altre sentit en funció del context i de les necessitats puntuals del predicador: així, el setge o la presa d'un castell poden simbolitzar en alguns casos l'encarnació i la vinguda al món de Jesucrist, però en d'altres poden representar, en canvi, les temptacions i els paranys que el dimoni para als homes o, encara, les bones obres mitjançant les quals l'ànima tracta d'assolir la salvació eterna.

\section{BIBLIOGRAFIA}

Allmand, C. (2011) The De Re Militari of Vegetius: The Reception, Transmission and Legacy of a Roman Text in the Middle Ages, Cambridge, Cambridge University Press.

Aquí, Tomàs d' (2006-2016) Catena Aurea. Glossa continua super Evangelia, ed. d'A. Guarienti, trad. de R. Coggi, Bolònia, Edizioni Studio Domenicano, 7 vols.

Autpert, A. (1536) In sancti Iohannis apostoli et evangelistae Apocalypsim libri decem, Colònia, Eucharium Cervicornum.

Badia, L. (1984) «Frontí i Vegeci, mestres de cavalleria en català als segles XIV i XV», Boletín de la Real Academia de Buenas Letras de Barcelona, 39, pp. 191-215.

Binkley, P. (1995) « John Bromyard and the Hereford Dominicans», a Drijvers, J.W. - MacDonald, A.A. (ed.) Centres of Learning: Learning and Location in PreModern Europe and the Near East, Leiden, Brill, pp. 255-264.

Boyle, L. (1973) «The date of the Summa praedicantium of John Bromyard», Speculum, 48, pp. 533-537.

Bromyard, J. (1586) Summa Praedicantium: omni eruditione refertissima, Venècia, apud Dominicum Nicolinum, 2 vols.

Carpentarius, A. (1582) Summa seu destructorium vitiorum, Venècia, ex officina Damiani Zenari.

Cátedra, P. (1994) Sociedad y literatura en la Edad Media. San Vicente Ferrer en Castilla (1411- 1412), Salamanca, Junta de Castilla y León.

Contamine, P. (1980) La guerre au Moyen Âge, París, Presses Universitaires de France.

Cornelius, R. (1930) The figurative castle, a study in the mediaeval allegory of the edifice, Bryn Mawr, Bryn Mawr University Press. 
Eiximenis, F. (1983) Lo Crestià, selecció i ed. d'A. Hauf, Barcelona, Edicions 62.

Ferrer, V. (1485) Sermones per tempus hyemale, Colònia, Heinrich Quentell.

Ferrer, V. (1975-1988) Sermons, III-VI, ed. de G. Schib, Barcelona, Ed. Barcino, 4 vols.

Ferrer, V. (1977) Sermons de Quaresma, ed. de M. Sanchis Guarner, València, Albatros, 2 vols.

Ferrer, V. (1995) Colección de sermones de Cuaresma y otros según el manuscrito de Ayora, ed. d'A. Robles, València, Ajuntament de València.

Ferrer, V. (2006) Sermonario de Perugia (Convento dei Domenicani, ms. 477), ed. de F. Gimeno Blay, València, Ajuntament de València.

Florència, A. de (1740) Sancti Antonini Archiepiscopi Florentini Ordinis Praedicatorum Summa Theologica in quattuor partes distributa, Verona, apud Augustinum Carattonium, 4 vols.

Gaffney, W. (1931) «The Allegory of the Christ-Knight in Piers Plowman», PMLA, 46 (1), pp. 155-168.

Garcia, V. (ed.) (2015) La traducció corellana de la Vita Christi de Ludolf de Saxònia (edició crítica i estudi traductològic del llibre Primer,València, 1496), València, Universitat de València [tesi doctoral].

Gupta, N.K. (2017) «Paul and the Militia Spiritualis Topos in 1 Thessalonians», a Dodson, J.R. — Pitts, A.W. (eds.) Paul and the Greco-Roman Philosophical Tradition, Londres, Bloomsbury, pp. 13-32.

Harnack, A. (1981) Militia Christi: The Christian Religion and the Military in the First Three Centuries, Filadèlfia, Fortress Press.

Hauf, A. (1997) «Manus habent: entorn als eufemismes amorosos de tipus miliar en el Tirant lo Blanc», a Barbera, J.M. (ed.) Actes del Col.loqui Internacional Tirant lo Blanc: L'albor de la novel.la moderna europea. Ais de Provença, 21-22 d'octubre de 1994. Estudis crítics sobre Tirant lo Blanc, Barcelona, Centre Aixois de Recherches Hispaniques - Institut Interuniversitari de Filologia Valenciana - Publicacions de l'Abadia de Montserrat, pp. 145-185.

Hauf, A. (2007) «Alguns aspectes interessants de la predicació vicentina», a Callado, E. (ed.) El fuego y la palabra: San Vicente Ferrer en el 550 aniversario de su canonización: actas del Ier Simposium Internacional Vicentino, Valencia, 26-29 de abril de 2005, València, Generalitat Valenciana, Conselleria de Cultura, Educació i Esport, pp. 145-162.

Hebron, M. (1997) The Medieval Siege: Theme and Image in Middle English Romance, Oxford, Clarendon Press.

Josep, F. (1956) Josephus, trad. d'H. St. J. Thackeray, Cambridge (Massachussets), Harvard University Press, 9 vols. 
Kaeuper, R. (2009) Holy Warriors. The Religious Ideology of Chivalry, Filadèlfia, University of Pennsylvania Press.

Krentz, W. (1993) «Military language and Metaphors in Philippians», a McLean, B.H. (ed.) Origins and Method. Towards a New Understanding of Judaism and Christianity. Essays in Honour of John C. Hurd, Sheffield, Sheffield Academic Press, pp. 105-127.

Langland, W. (1987) The Vision of Piers Plowman: the B-text, ed. d'A.V.C. Schmidt, Londres, Everyman Press.

Leclercq, J. (1992) «Militare Deo dans la tradition patristique et monastique», a Militia Christi e crociata nei secoli XI-XIII. Atti della undecima Settimana internazionale di studio (Mendola, 28 agosto - 1 settembre 1989), Milà, Pubblicazioni dell’Università Cattolica del Sacro Cuore, pp. 3-20.

López de Mendoza, Í. (1997) Comedieta de Ponza, sonetos, serranillas y otras obras, ed. de V. Beltran, Barcelona, Crítica.

Lutz, J. - Perdrizet, P. (ed.) (1907) Speculum Humanae Salvationis, Die Quellen des Speculum und sine Bedeutung in der Ikonographie besonders in der clässichen Kunst des XIV Jahrhunderts, Buchdruckerei Ernst Meininger, Leipzig, 2 vols.

Manrique, J. (2013) Poesía, ed. de V. Beltran, Madrid, Real Academia Española.

Martínez, T. (2002) Aproximació als sermons de sant Vicent Ferrer, Paiporta, Denes.

Martorell, J. (2004) Tirant lo Blanch, ed. i notes d'A. Hauf, València, Editorial Tirant lo Blanch.

Migne, J.P. (ed.) (1844-1865) Patrologiae latinae cursus completus, París, Imprimerie Catholique, 217 vols.

Muntaner, R. (2011) Les quatre grans Cròniques. III: Crònica de Ramon Muntaner, ed. de F. Soldevila (revisió filològica de J. Bruguera; revisió històrica de M.T. Ferrer i Mallol), Barcelona, Institut d'Estudis Catalans.

Peltier, (ed.) (1864-1871) Opera Omnia Sancti Bonaventurae, París, Vives, 15 vols.

Perarnau, J. (1996) «Els quatre sermons catalans de sant Vicent Ferrer en el manuscrit 476 de la Biblioteca de Catalunya», Arxiu de Textos Catalans Antics, 15, pp. 109-340.

Perarnau, J. (1999) «Aportació a un inventari de sermons de sant Vicenç Ferrer: temes bíblics, títols i divisions esquemàtiques», Arxiu de Textos Catalans Antics, 18, pp. 479-811.

$\mathrm{PL}=$ Patrologia Latina . Vegeu Migne (1844-1865).

Renedo, X. (2007) «Del quadern al sermó, i del sermó al manuscrit. Unitat i diversitat en els sermons de Sant Vicent Ferrer», a Callado, E. (coord.) El 
fuego y la palabra: San Vicente Ferrer en el 550 aniversario de su canonización: actas del ler Simposium Internacional Vicentino: Valencia, 26 - 29 de abril de 2005, València, Generalitat Valenciana, pp. 89-110.

Saint Cher, H. de (1703) Hugonis cardinalis opera omnia in universum Vetus, et Novum Testamentum, Venècia, apud Nicolaum Pezzana, 8 vols.

San Gimignano, G. da (1597) Summa de exemplis et rerum similitudinibus locupletissima, Anvers, in aedibus Petri Belleri.

Sant Jordi, J. de (1984) Les poesies de Jordi de Sant Jordi, ed. de M. de Riquer i L. Badia, Barcelona, Tres i Quatre.

Siena, B. de (1650) Sancti Bernardini Senensis, Ordinis Seraphici Minorum Opera omnia, Lyon, sumptibus Ioannis Antonii Huguetan et Marci Antonii Ravaud, 5 vols.

Smith, K.A. (2011) War and the Making of Medieval Monastic Culture, Woodbridge, The Boydell Press.

Villena, I. de (1995) Vita Christi, selecció i ed. d'A. Hauf, Barcelona, Edicions 62.

Warner, L. (1996) «Jesus the Jouster: The Christ-Knight and Medieval Theories of Atonement in Piers Plowman and the "Round Table" Sermons», The Yearbook of Langland Studies, 10, pp. 129-143.

Wenzel, S. (1986) Preachers, Poets and the Early English Lyric, Princeton, Princeton University Press.

Wenzel, S. (ed.) (1989) Fasciculus Morum. A Fourteenth-Century Preacher's Handbook, University Park, The Pennsylvania State University Press.

Wheatley, A. (2004) The Idea of the Castle in Medieval England, Woodbridge, York Medieval Press.

Ysern, J.A. (2015) Como una red. Sermones de Vicent Ferrer, València, Publicacions de la Universitat de València.

Ysern, J.A. (2019) «Armes, armadures i batalles al-legòriques en els sermons de sant Vicent Ferrer», Anuario de Estudios Medievales, 49 (1), pp. 287-312. 